NASA/TM-2001-210842

ARL-TR-2432
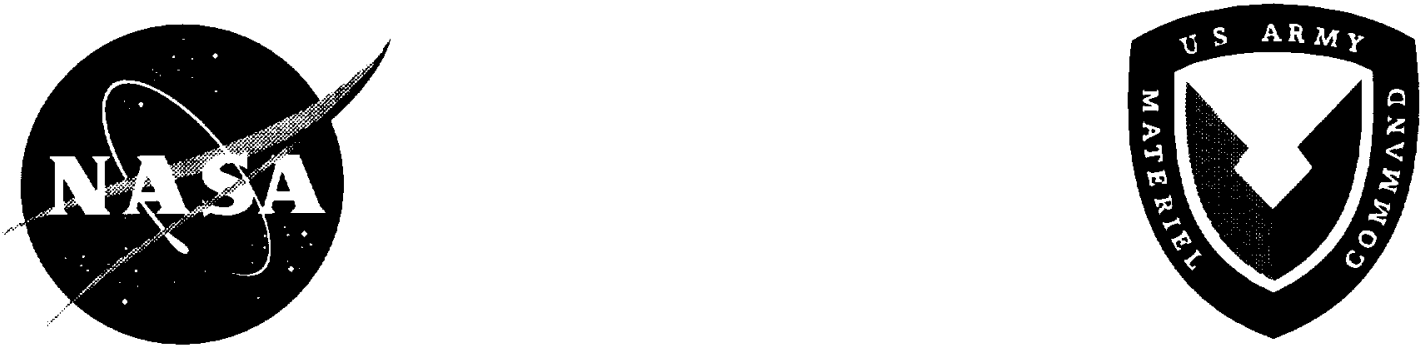

\title{
Fatigue Life Methodology for Bonded Composite Skin/Stringer Configurations
}

Ronald Krueger

ICASE

Langley Research Center, Hampton, Virginia

Isabelle L. Paris

Langley Research Center, Hampton, Virginia

T. Kevin O'Brien

U.S. Army Research Laboratory

Vehicle Technology Directorate

Langley Research Center, Hampton, Virginia

Pierre J. Minguet

The Boeing Company

Philadelphia, Pennsylvania

National Aeronautics and

Space Administration

Langley Research Center

Hampton, Virginia 23681-2199 
The use of trademarks or names of manufacturers in the report is for accurate reporting and does not constitute an official endorsement, either expressed or implied, of such products or manufacturers by the National Aeronautics and Space Administration or the U.S. Army.

Available from:

NASA Center for AeroSpace Information (CASI)

7121 Standard Drive

Hanover, MD 21076-1320

(301) 621-0390

National Technical Information Service (NTIS) 5285 Port Royal Road

Springfield. VA 22161-2171

(703) 605-6000 


\title{
FATIGUE LIFE METHODOLOGY FOR BONDED COMPOSITE SKIN/STRINGER CONFIGURATIONS
}

\author{
Ronald Krueger', Isabelle L. Paris ${ }^{2}$ and T. Kevin O'Brien ${ }^{3}$ \\ ${ }^{1}$ ICASE Staff Scientist \\ ${ }^{2}$ National Research Council Research Associate \\ ${ }^{3}$ U.S. Army Research Laboratory, Vehicle Technology Directorate \\ NASA Langley Research Center \\ Hampton, VA 23681-2199
}

\begin{abstract}
A methodology is presented for determining the fatigue life of composite structures based on fatigue characterization data and geometric nonlinear finite element analyses. To demonstrate the approach, predicted results were compared to fatigue tests performed on specimens which consisted of a tapered composite flange, representing a stringer or frame, bonded onto a composite skin. In a first step, quasi-static tension and fatigue tests were performed to evaluate the debonding mechanisms between the skin and the bonded stringer. Specimen edges were examined under the microscope to document the damage occurrence. In a second step, a two-dimensional finite element model was developed to analyze the tests. To predict matrix cracking onset, the relationship between the externally applied tension load and the maximum principal stresses transverse to the fiber direction was determined through geometrically nonlinear analysis. Transverse tension fatigue life data were used to generate an onset fatigue life P-N curve for matrix cracking. The resulting prediction was in good agreement with measured data from the fatigue tests. In a third step, a fracture mechanics approach based on geometrically nonlinear analysis was used to determine the relationship between the externally applied tension load and the critical energy release rate. Mixed mode energy release rate fatigue life data from $\mathrm{DCB}, 4 \mathrm{ENF}$ and $\mathrm{MMB}$ tests were used to create an fatigue life onset G-N curve for delamination. The resulting prediction was in good agreement with data from the fatigue tests. Additionally, the prediction curve for cumulative life to failure was generated from the matrix onset and delamination onset fatigue life curves. The results were in good agreement with data from the fatigue tests which demonstrated that the methodology offers a significant potential to predict cumulative fatigue life of composite structures.
\end{abstract}




\section{KEY WORDS}

Composite materials, testing, finite element analysis, fatigue life prediction, fracture mechanics, skin/flange interface

\section{INTRODUCTION}

Many composite components in aerospace structures are made of flat or curved panels with cocured or adhesively bonded frames and stiffeners. Testing of stiffened panels designed for pressurized aircraft fuselage has shown that bond failure at the tip of the frame flange is an important and very likely failure mode |1|. Comparatively simple specimens consisting of a stringer flange bonded onto a skin have been developed to study skin/stiffener debonding. The failure that initiates at the tip of the flange in these specimens is identical to the failure observed in the full-scale panels and the frame pull-off specimens [2-6].

The overall objective of this work was to develop a methodology for cumulative life prediction of bonded composite skin/stringer structures using delamination fatigue characterization data and a geometric nonlinear finite element analysis similar to the approach used for composite rotor hub flexbeams $|7|$. Results were compared to fatigue tests on stringer flange/skin specimens to verify the methodology.

The damage mechanisms in bonded composite skin/stringer structures under tension fatigue loading conditions were documented. The specimens consisted of a tapered flange, representing the stringer bonded onto a skin. Static tension tests were performed to evaluate the debonding mechanisms between the skin and the bonded flange and yield static failure loads. Then, tension fatigue tests were performed at load levels corresponding to $40,50,60$, and $70 \%$ of the damage onset loads. Microscopic investigations of the specimen edges were used to identify typical damage patterns and to document the onset of matrix cracking and delamination as a function of fatigue cycles.

Next, an analytical methodology to accurately predict the onset of matrix cracking as well as delamination was demonstrated. The tension loading was simulated in a geometrically nonlinear plane-stress finite element model. A stress analysis was used to predict the location and orientation of the first transverse crack based on the principal transverse tension stress distribution in the flange tip area. Computed stresses for different load levels were compared to material characterization data from transverse tensile fatigue tests to generate a curve predicting the onset of matrix cracking. A fracture mechanics approach was used to determine delamination growth from this transverse crack. Delaminations of various lengths were discretely modeled by releasing multipoint constraints at the locations where delaminations were observed during the experiments. Mode I and II strain energy 
release rate contributions, $G_{1}$ and $G_{11}$, were calculated for all load cases using the virtual crack closure technique. Computed peak $G$ values were used with $G$ versus $N$ fatigue characterization data generated using DCB, ENF and MMB specimens to predict the fatigue life of the skin/stringer specimens. A cumulative life prediction methodology was developed by combining the results for fatigue life for matrix crack onset and fatigue life for delamination onset.

\section{EXPERIMENTAL INVESTIGATION}

\section{MATERIALS AND SPECIMEN PREPARATION}

The specimens consisted of a tapered laminate, representing the stringer, bonded onto a skin as shown in Figure 1. An IM7/8552 graphite/epoxy system was used for both the skin and flange. The skin was made of prepreg tape and had a nominal ply thickness of $0.142 \mathrm{~mm}$ and a $[45 /-45 / 0 /-45 / 45 / 90 / 90 /-45 / 45 / 0 / 45 /-45]$ lay-up. The flange was made of a plain-weave fabric of $0.208 \mathrm{~mm}$ nominal ply thickness. The flange lay-up was $[45 / 0 / 45 / 0 / 45 / 0 / 45 / 0 / 45]_{\mathrm{f}}$, where 0 represents a $0^{\circ}-90^{\circ}$ fabric ply and 45 represents a $0^{\circ}-90^{\circ}$ fabric ply rotated by $45^{\circ}$.

The flange was pre-cured, cut to size, machined with a $25^{\circ}$ taper along the edges and co-bonded with the uncured skin using one ply of grade 5, FM300 adhesive film. A diamond saw was used to cut the panels into $25.4 \mathrm{~mm}$ wide by $177.8 \mathrm{~mm}$ long specimens. The average ply thickness obtained from specimen thickness measurements and micrographs was $0.148 \mathrm{~mm}$ for the tape, $0.212 \mathrm{~mm}$ for the fabric and $0.178 \mathrm{~mm}$ for the adhesive. The properties of the graphite/epoxy material and the adhesive were measured at Boeing and are part of the standard design database for the V-22 tiltrotor aircraft. Typical properties are summarized in Table $I$. The specimen dimensions are shown in Figure 1.

\section{EXPERIMENTAL PROCEDURE}

Quasi-static tension tests were performed in a servohydraulic load frame in displacement control at a stroke rate of $0.4 \mathrm{~mm} / \mathrm{min}$. The specimens were mounted in hydraulic grips with a gage length of $101.6 \mathrm{~mm}$ as shown in Figure 2. A total of 4 specimens were tested. One specimens was equipped with two strain gages, one located in the center of the flange and the other located on the skin as close to the flange tip as possible (Figure 1). The remaining three specimens had the gage on the flange only. In addition to the strain gages, an extensometer with a $25.4 \mathrm{~mm}$ gage length was 
mounted on the backside of the specimen and centered on the flange tip as shown in Figure 2. A damage onset load was determined at which a small initial load drop was observed prior to flange debonding. The value of the damage onset load was averaged from four tests and determined to be $17.8 \mathrm{kN}$ which was later designated as $P_{100 \%}$. The tests were terminated when the flange debonded from the skin.

Fatigue tests were performed at a cyclic frequency of $5 \mathrm{~Hz}$, an R-ratio of 0.1 and load levels corresponding to $70 \%, 60 \%, 50 \%$ and $40 \%$ of the quasi-static damage onset load. Three tests were performed at $70 \%$ and $50 \%$ and four tests were performed at $60 \%$ and $40 \%$. The damage was monitored using a Questar digital microscope on one edge and an optical travelling microscope on the other edge. The specimen edges were painted white to make the cracks and delaminations more visible. Damage was documented based on location at each of the four corners identified in Figure 1. The number of cycles at which the first matrix crack appeared was recorded as well as the number of cycles to delamination onset. After the test, photographs of the polished specimen edges were taken under a light microscope to document the occurrence of matrix cracking and delamination. For two specimens, at intervals of damage growth, the test was stopped and the specimens removed from the grips. Photographs of the polished specimen edges were then taken under a light microscope to document the progression of the damage.

\section{MICROSCOPIC INVESTIGATION}

Typical damage patterns observed from specimens are shown in Figures 3-5. The included drawings are based on edge observations during the tests and micrographs taken during and after the tests. All quasi-static and fatigue tests yielded similar damage patterns. Under quasi-static loading, failure occurred across one flange tip of the specimen only, with no clear preference for corners 1 and 2 or corners 3 and 4 . In fatigue, damage initiated at both flange tips, but not at the same time.

At corners 2 and 3, a delamination (delamination B) formed in the top $45^{\circ} / 45^{\circ}$ skin ply interface, as depicted in Figure 3a. In the static tests, the damage was only observed after the test. Delamination appeared to initiate at the flange tip from a matrix crack in the top $45^{\circ}$ skin ply as shown in Figure $3 \mathrm{~b}$. In fatigue, the sequence of events was observed with the Questar microscope. Micrographs of the polished edge, as shown in Figure 4, were also taken at intervals. The first matrix crack occurred in the adhesive pocket, then grew through the top $45^{\circ}$ skin ply and formed a delamination in the top $45^{\circ} /-45^{\circ}$ skin ply interface, growing towards the center of the flange. Sometimes, the delamination grew back towards the grip and coalesced with a matrix crack in the 
top $45^{\circ}$ ply further from the flange.

At corners 1 and 4, a delamination running in the bondline (delamination Al) initiated from a matrix crack in the adhesive pocket as shown in Figure 5. In some of the quasi-static cases, a second delamination (A2) was observed below the first, in the top $-45^{\circ} / 0^{\circ}$ skin ply interface. Delamination A2 was not observed in fatigue. In the fatigue tests, damage first appeared at corner 2 and 3 (delamination B) for 12 of the 14 specimens.

\section{TEST RESULTS}

In Figures 6 to 8, typical results of the four quasi-static tension tests are shown as plots of load versus displacement or strain versus load. Results from finite element analyses, which are included in the figures, will be discussed later. As shown in Figure 6, the load-displacement curves were slightly nonlinear. Possible damage initiation was assumed when a small initial load drop was observed in two of the tests prior to flange debonding. At this point, a crack in one flange tip or even a small delamination along one flange corner was observed. In two specimens, no initial load drop or visible damage could be detected. In general, the initial load drop occurred above $90 \%$ of the maximum sustained load. Figure 7 shows the nonlinear strain-load response up to the point of flange debonding. Initially, flange strains dropped before rising again with increasing load. In all specimens, a load drop was also accompanied by a decrease in strain. The same two specimens that showed a small initial load drop in the load-displacement plots also displayed a drop in flange strain prior to flange debonding. Skin strains were nearly linear until flange debonding occurred, as shown in Figure 8.

The tension fatigue failure of the specimens was characterized by plotting the applied tension load versus the number of load cycles at damage onset. The number of cycles to matrix crack onset and delamination onset were plotted for each specimen as shown in Figures 9 and 10. The static strength values obtained from the quasi-static tests were also added to Figure 9 at $N=1$ to complement the graph. A noticeable distinction between matrix crack onset and delamination onset becomes apparent when plotting the mean values only as shown in Figure 11. An almost linear relationship between $P_{\max }$ and $\log N$ was observed. 


\section{ANALYTICAL INVESTIGATION}

\section{FINITE ELEMENT ANALYSIS}

The finite element (FE) method was used to study damage initiation using a stress analysis and to study the potential for delamination using fracture mechanics. The schematics of the twodimensional model of the specimen, boundary conditions, and loads applied are shown in Figure 12. FE models for one undamaged and three damaged specimens were developed. Finite element solutions were obtained using the commercial ABAQUS ${ }^{\text {Ti }} /$ Standard finite element software. Eight-noded quadrilateral plane-stress (CPS8R) and plane-strain (CPE8R) elements with quadratic shape functions and a reduced $(2 \times 2)$ integration scheme were utilized for the geometric nonlinear analyses [8].

For the model of the undamaged specimen, a refined mesh was used in the critical area of the $45^{\circ}$ skin ply where cracking was observed during the tests. An outline and two detailed views of the mesh are shown in Figure 12. Outside the mesh refinement area, all plies were modeled with one element through the ply thickness. In the refined region, four elements were used per ply thickness for the first two individual flange plies above the bondline and the top skin ply below the bondline. Four elements through the thickness were also used to model the adhesive film. Typical ply properties and adhesive material properties used in this study are summarized in Table I.

Based upon examinations of tested specimens, the critical damage was assumed to start at corners 2 and 3 in the form of a matrix crack in the top $45^{\circ}$ skin ply that developed into a delamination in the $45^{\circ} /-45^{\circ}$ interface as shown in Figure 3. Therefore, damage was modeled at one flange tip only as shown in Figure 13a. At the opposite taper, the original mesh created for the model of the undamaged specimen was used. Damage was modeled as discrete discontinuities as shown in Figure 13. Based on the experimental observations shown in Figure 4, three different locations were selected for the origin of the matrix crack in the models. This was done to determine how the matrix crack origin influenced the energy release rate computed as a function of delamination length for a delamination growing in the $45^{\circ} /-45^{\circ}$ interface.

It is inherent to a two dimensional FE model that the geometry, boundary conditions and other properties are constant across the entire width of the model. This may not always capture the true nature of the problem. As shown in Figures 3 and 5, the delamination pattern changed from corner 3 to corner 4 from a delamination running in the $45^{\circ} / 45^{\circ}$ interface to a delamination propagating in the bondline. These three-dimensional patterns of matrix cracks and delaminations, which vary across the width of the specimen, can not be accounted for in any two-dimensional FE model. In addition, the plane-stress model imposes $\sigma_{z z}=\tau_{x z}=\tau_{y z}=0$ at the free edge of each ply and allows the displacement to be the free parameter. The plane-strain model, on the other hand, 
imposes $\varepsilon_{z z}=\gamma_{x z}=\gamma_{y z}=0$ at the free edge, which excessively constrains the plies. An alternative to a full three-dimensional simulation might be a generalized plane-strain model, which requires about the same modeling effort as a simple two-dimensional model [9|. The generalized plane-strain case may be regarded as an intermediate state, and it is assumed that $\varepsilon_{z z}=-\nu_{\mathrm{L}} \varepsilon_{\mathrm{xx}}$ and $\gamma_{\mathrm{xz}}=\gamma_{\mathrm{yz}}=0$ where $\nu_{\mathrm{L}}$ is the laminate Poisson's ratio. The current study, however, was restricted to the use of twodimensional models to demonstrate the methodology.

The Virtual Crack Closure Technique (VCCT) described in references [10| and [11] was used to calculate strain energy release rates for the delaminations. The mode I and mode II components of the strain energy release rate, $G_{1}$ and $G_{\mathrm{II}}$, were calculated as

$$
\mathrm{G}_{\mathrm{I}}=-\frac{1}{2 \Delta \mathrm{a}}\left[\mathrm{Y}_{\mathrm{i}}^{\prime}\left(\mathrm{v}_{\mathrm{m}}^{\prime}-\mathrm{v}_{\mathrm{m}}^{\prime}{ }^{*}\right)+\mathrm{Y}_{j}^{\prime}\left(\mathrm{v}_{\ell}^{\prime}-\mathrm{v}_{\ell}^{\prime}\right)\right]
$$

and

$$
G_{I I}=-\frac{1}{2 \Delta a}\left[X_{i}^{\prime}\left(u_{m}^{\prime}-u_{m}^{\prime}\right)+X_{j}^{\prime}\left(u_{\ell}^{\prime}-u_{\ell}^{\prime}\right)\right]
$$

where $\Delta \mathrm{a}$ is the length of the elements at the crack tip, $X_{i}^{\prime}$ and $Y_{i}^{\prime}$ are the forces at the delamination tip at node $i$, and $u_{m}{ }^{\prime}$ and $v_{m}{ }^{\prime}$ are the relative displacements at the corresponding node $m$ behind the delamination tip as shown in Figure 14. Similar definitions are applicable for the forces at node $j$ and displacements at node $\ell$. Both forces and displacements were transformed into a local coordinate system $\left(x^{\prime}, y^{\prime}\right)$, that defined the normal and tangential coordinate directions at the delamination tip in the deformed configuration. The mode III component is identically zero for all the two-dimensional cases evaluated. Therefore, the total strain energy release rate, $G_{T}$, was obtained by summing the individual mode components as

$$
\mathrm{G}_{\mathrm{T}}=\mathrm{G}_{\mathrm{I}}+\mathrm{G}_{\mathrm{II}}
$$

The data required to perform the VCCT in equations (1) to (3) were accessed directly from the ABAQUS $^{\oplus}$ binary result file to get better accuracy. The calculations were performed in a separate post-processing step using nodal displacements and nodal forces at the local elements in the vicinity of the delamination front. Details are given in the appendix.

Care must be exercised in interpreting the values for $G_{\mid}$and $G_{\|}$obtained using the virtual crack closure technique for interfacial delaminations between two orthotropic solids as the observed oscillatory singularity at the crack tip becomes an issue for small element lengths $\mid 12,13]$. Hence, it had been suggested to use element lengths $\Delta a$ at the crack tip in such a manner that the computed results are insensitive to the variation of $\Delta a$. For practical applications, the element size (length and height) should not be less than 1/10 of a ply thickness, which corresponds to the diameter of two 
carbon tows in the carbon/epoxy material modeled. For smaller element sizes the assumption of modeling each ply as an orthotropic continuous layer is no longer valid. For the current investigation, therefore, the element length $\Delta a$ was chosen to be about $1 / 3$ of the ply thickness, $\mathrm{h}=0.148 \mathrm{~mm}$, for the delamination in the $45^{\circ} /-45^{\circ}$ flange ply interface. Note that for the FE models shown in Figure $13 \mathrm{c}$ and $\mathrm{d} \Delta \mathrm{a} h=0.169$ for the first element in the delaminated zone and $\Delta a h=0.338$ for the following elements. Consequently, the technique suggested in reference $[10]$ was used to estimate the forces $X_{i}^{\prime}$ and $Y_{i}^{\prime}$ for the case of unequal element lengths at the delamination tip. For all subsequent delamination growth, a value of $\Delta a / h=0.338$ was used.

\section{GLOBAL RESPONSE}

First, the global response of the specimens was computed at the mean quasi-static damage onset load $\left(P_{100 \%}=17.8 \mathrm{kN}\right)$ determined from experiments. The load-displacement and the load-strain behavior computed were compared to the corresponding experimental results. This global response was used to examine whether the FE model, the boundary conditions, the loads and the material properties used in the model were accurate. Calculated displacements are reported for the locations where they were measured in the quasi-static experiments. Strains were averaged from computed nodal point values over a length corresponding to the dimensions of the strain gages.

A schematic of the deformed geometry, the boundary conditions, and the load applied in the simulations are shown in Figure 15. In the schematic, the elongation of the specimen caused by the applied tensile load is shown. Also visible is the bending effect caused by the load eccentricity in the flange region, the asymmetric layup with respect to the neutral axis, and the membrane stiffening effect. The extensometer displacement plots in Figure 6 show that there is good agreement between the analyses and the experiments; the models therefore captured the global response. As expected, the specimen shows a stiffer behavior than the experiments when modeled with plane-strain elements. The plane-stress model, on the other hand, is more compliant. A comparison of measured strains at the surface of the flange and computed results is shown in Figure 7. The nonlinear analysis yielded results that were in close agreement with the experiments. Again, the plane-strain models were stiffer, and the plane-stress models more compliant compared to the tested specimens. The linear analysis for both cases, however, was not able to capture the transition from compressive flange strains at the beginning to tension flange strains at the end of the loading. Hence, a geometrically nonlinear FE analysis is necessary to account for the effects due to the load eccentricity in the flange region, the asymmetric layup with respect to the neutral axis, and the membrane stiffening effect. In Figure 8, measured strains at the surface of the top $45^{\circ}$ skin ply near 
the flange tip (see Figure 1) and computed surface strains were compared. As mentioned above, the plane-strain models showed a stiffer behavior and the plane-stress models a more compliant behavior compared to the tested specimens. The strain-load responses obtained from the nonlinear plane-stress analysis are in better agreement with the experiments compared to the values obtained from the other analyses. This result is of particular interest as the failure observed in the experiments occurred in top $45^{\circ}$ skin ply where the strain gage was mounted near the tip of the flange as shown in Figures 3 to 5 . Hence, the geometrically nonlinear plane-stress FE analysis was used for the remainder of this study as it produced the most accurate results in the area of interest.

\section{LOCAL RESPONSE}

A stress analysis was used to study the initial damage in the form of matrix cracks from which delaminations may start to grow. As shown in Figures 3 to 5, the matrix crack always occurred in the top $45^{\circ}$ skin ply near the flange tip. Earlier investigations 12,3$]$ indicated that the matrix cracking occurred when the maximum principal transverse tensile stress, $\sigma_{t t}$, normal to the fiber direction, as calculated by

$$
\sigma_{\mathrm{tt}}=\frac{\sigma_{22}+\sigma_{33}}{2}+\sqrt{\left(\frac{\sigma_{22}-\sigma_{33}}{2}\right)^{2}+\tau_{23}^{2}}
$$

reached the transverse tension strength of the material (Figure 16). The computed maximum principal tensile stress was calculated for the static failure load using plane-stress and plane-strain models. The stress distribution in the top $45^{\circ}$ skin ply is plotted in the immediate vicinity of the flange tip in Figure 17. In the graph, $x=0$ corresponds to left grip as shown in Figures 12 and 15. and $x=26.4$ corresponds to the left flange tip. The transverse tensile strength for IM7/8552 obtained from three-point bending test of $90^{\circ}$ lamina was included in the plot for comparison. Stresses at the static failure load computed from the plane-stress analysis correspond well with the transverse tensile strength. Stresses from the plane-strain analysis are excessively high. This is caused by the constraints inherent to the plane-strain model, particularly in the $\pm 45^{\circ}$ plies. These findings support the conclusions drawn from the comparison of computed and measured skin strains in the previous paragraph. Hence, the geometrically nonlinear plane-stress FE analysis was used for the remainder of this study as it appeared to produced the most accurate results in the area of interest. The computed maximum principal tensile stress calculated from plane-stress analyses for all fatigue load levels are plotted in Figure 18. During the fatigue tests, first matrix cracking was observed at locations right next to the flange tip (Figure 5) which corresponds to the location where 
peak stresses were calculated.

A fracture mechanics approach was used to investigate delamination onset once the initial crack had formed. The Virtual Crack Closure Technique (VCCT) was used to calculate the mode I and II components of the strain energy release rates for the delamination. The initial crack was modeled at a location as suggested by the microscopic investigation and the stress analysis described in the previous paragraph. Recall that the models of the discrete matrix cracks and delaminations are shown in Figure 13. For this investigation, the delamination growing between the skin top $45^{\circ}$ and $-45^{\circ}$ plies was extended by releasing multi-point constraints at the crack tip and in front of the crack tip. During a series of nonlinear finite element analyses, strain energy release rates were computed at each tip location for the loads applied in the experiments. A critical energy release rate, $G_{c}$, needs to be determined to predict delamination onset. This critical $G$ is generally identified based on the shape of the total energy release rate versus delamination length curve, which is determined through analysis as shown in Figure 19 . The $G_{T}$ versus $x$ curve reached a peak at some virtual delamination length and then decreased. The delamination was extended to a total simulated length of $2.2 \mathrm{~mm}$ to ascertain that the peak value had been captured. The total energy release rates computed for all load levels are plotted in Figure 19. To determine the influence of the initial matrix crack location corresponding to the models shown in Figure 13, the total energy release rates and the corresponding mixed mode ratios $G_{||} / G_{T}$ at $P_{100 \%}$ were plotted in Figures 20 and 21 . The results demonstrated that the computed energy release rates and corresponding mixed mode ratios did not depend on the location of the matrix crack that initiated the delamination. A slight discrepancy was only noticeable up to the first four increments of delamination growth. For longer delamination lengths the results for all three cracked models were identical. Hence, the maximum total energy release rate, $G_{\top}$, was chosen as the critical value to be used for the fatigue life prediction. This peak in $G_{T}$ also corresponded to the maximum mode $I$ percentage, i.e., minimum value of $G_{11} / G_{T}$ in Figure 21 . 


\section{METHODOLOGY FOR FATIGUE LIFE PREDICTION}

For a particular structural component and loading of interest, the cumulative life to failure, $N_{T}$, may involve the onset and growth of several cracks and delaminations. For example, $N_{T}$ may be predicted by summing the lives for onset of matrix cracking, $N_{M}$, delamination onset from this matrix crack, $N_{D}$, and stable delamination growth to a finite acceptable delamination size, $N_{G}$. Hence,

$$
N_{T}=N_{M}+N_{D}+N_{G}
$$

The current study focussed on the prediction of damage onset only. Hence, stable delamination growth to a finite acceptable delamination size was not considered and the total cumulative life to failure was

$$
N_{T}=N_{M}+N_{D}
$$

\section{MATRIX CRACKING ONSET FATIGUE LIFE PREDICTION}

Matrix cracking was the first damage mechanism to occur in the specimen and was followed by delamination. In order to predict the onset of matrix cracking, the following steps were taken.

In Figure 22, the relationship between the externally applied tensile load, $\mathrm{P}$, and the principal transverse tensile stresses, $\sigma_{\mathrm{tt}}$, in the top $45^{\circ}$ skin ply was determined by plotting the loads versus the peak stresses from Figure 18. To account for residual stresses after cooldown and moisture absorption, a simple analysis was performed using classical laminate theory. Since the flange had already been cured before it was adhesively bonded to the skin it was not included in the calculation of the residual stresses. Coefficients of hygrothermal expansion were not available for IM7/8552. Therefore, data from similar types of carbon/epoxy prepreg were taken from the literature [14]. The values used in the calculation were: $\alpha_{x}=0.6 \times 10^{6} 1 / \mathrm{K}, \alpha_{y}=28.6 \times 10^{6} 1 / \mathrm{K}$ for the coefficients of thermal expansion in parallel and transverse direction of the fibers and $\beta_{x}=0.0, \beta_{y}=0.664$ (dimensionless) for the coefficients of moisture expansion. The temperature difference between curing and room temperature was assumed to be $\Delta T=157 \mathrm{~K}$. The moisture content of the specimens was measured by drying five specimens and comparing the mass before and after drying. The average moisture content was determined to be 0.0042 of the specimen mass. It was assumed that the residual stresses existed prior to testing and were not altered during the fatigue tests. This means that the tests were performed at frequencies which did not result in a temperature increase 
and therefore did not relax the stresses. Hence, the calculated residual stress was simply added to the transverse tensile stresses obtained from finite element analysis. These results were also included in Figure 22.

The transverse tension fatigue life of IM7/8552 carbon-epoxy was characterized using flexure tests of $90^{\circ}$ laminates loaded in three point bending. A fatigue onset life characterization curve was generated using data from three-point bending tests performed at a frequency of $10 \mathrm{~Hz}$ and a load ratio of $R=0.1$. The transverse tensile stress $\sigma_{t \operatorname{tmax}}$, (where "max" refers to the maximum stress resulting from the sinusoidal cyclic load applied) was determined from beam theory as

$$
\sigma_{\max }=\frac{3 P_{\max } \cdot s}{2 b \cdot t^{2}}
$$

and was plotted versus the number of cycles to failure, $N$ as shown in Figure 23. Here $P_{\max }$ is the maximum of the sinusoidal cyclic load applied, $s$ is the span between the supports, $b$ is the average specimen width and $t$ is the average thickness of the three point bending specimen. The fatigue life curve in Figure 23 was obtained by curve fit of the mean life data. Additionally, scatter was addressed by constructing curves with plus and minus one standard deviation, which were included in Figure 23.

Once these calculations and characterizations were available, it was possible to determine for an arbitrary maximum cyclic load, $\left(P_{i}\right.$ in Figure 22$)$, the maximum transverse tensile stress $\left(\sigma_{i}\right.$ in Figure 22) as well as the associated fatigue life ( $N_{i}$ in Figure 23). Plotting the relationship between the externally applied load, $P$, and the fatigue life for onset of matrix cracking, $N_{M}$, yielded the prediction onset curve as shown in Figure 24. This procedure was repeated using the curves with plus and minus one standard deviation in Figure 23 to obtain the set of curves in Figure 24 . The prediction for matrix cracking onset in the skin/stiffener specimens agreed reasonably well with measured P-N data from the fatigue tests which were included in Figure 24. However, significant deviation was noted between measured and predicted onset loads under monotonically increasing (quasi-static) loads. Alternate characterization test methods may ultimately prove more useful than three-point-bending test of $90^{\circ}$ laminates. However, only this method was used in this study to demonstrate the methodology. 


\section{DELAMINATION ONSET FATIGUE LIFE PREDICTION}

Delaminations originated from the matrix cracks as shown in Figures 3 to 5 . In order to predict delamination onset, a quasi static mixed-mode fracture criterion had to be determined first |15|. This was accomplished by plotting $G_{c}$ versus the mixed-mode ratio, $G_{\|} / G_{T}$, determined from data generated using pure Mode I DCB $\left(G_{\|} / G_{T}=0\right)$, pure Mode II $4 E N F\left(G_{\|} / G_{T}=1\right)$, and mixed-mode MMB tests of varying ratios, as shown in Figure 25 for IM7/8552 [16]. A curve fit of these data was performed to determine a mathematical relationship between $G_{c}$ and $G_{\|} / G_{T}$. Based on this type of fracture criterion, the following steps were taken to determine the delamination onset life.

First, the relationship between the externally applied load, $P$, and the total energy release rate, $G_{T}$, was determined by plotting $P$ versus peak $G_{T}$ (from Figure 19) as shown in Figure 26 for several load cases and fitting a curve to these results. Additionally, the corresponding mixed-mode ratio, $\mathrm{G}_{\mid} / \mathrm{G}_{\mathrm{T}}$, was calculated at each load step, and the results were also curve fit and plotted in Figure 26. Due to a minimal variation in the mixed mode ratio, an average constant $G_{\|} / G_{T}=0.18$ was assumed for the following step.

Second, a failure surface as shown in Figure 27 , relating the total energy release rate, $G_{\max }$, to the mixed mode ratio, $G_{\|} / G_{T}$, and the number of cycles to delamination onset, $N$, was created. The surface was fit through data from fatigue experiments using DCB, 4ENF, and MMB tests |16|. The quasi-static mixed mode failure criterion, as shown in Figure 25, is represented in Figure 27 by the plane at $\log N=0(N=1)$. From the failure surface an appropriate fatigue life curve (shown in Figure 28) was extracted for $G_{\|} / G_{T}=0.18$, which corresponds to the calculated average mixed mode ratio from above.

Then, with this information available, for an arbitrary maximum cyclic load, $P_{i}$, the total energy release rate, $G_{i}$, was determined as illustrated in Figure 26 . The associated fatigue life, $N_{i}$, was obtained as shown in Figure 28.

Finally, plotting the relationship between the externally applied load, $P$, and the fatigue life for delamination onset, $N_{D}$, yielded the prediction onset curve as shown in Figure 29. The measured P-N data from the fatigue tests, corresponding to the total life to delamination onset (Figure 10) minus the life to matrix cracking onset (Figure 9), were included in Figure 29 for verification. The prediction for delamination onset is in good agreement with the experimental observations. 


\section{CUMULATIVE LIFE PREDICTION}

The prediction curve for cumulative life to onset of failure

$$
N_{T}=N_{M}+N_{D}
$$

is plotted in Figure 30. For verification the measured P-N data from the fatigue tests, corresponding to the total life to delamination onset in Figure 10, were included in the plot of Figure 30. For

higher number of cycles $\left(\mathrm{N}_{T}>10^{2}\right)$ the prediction for delamination onset is in good agreement with the experimental observations. However, agreement was not as good for low load cycles $\left(\mathrm{N}_{T}<10^{2}\right)$, primarily reflecting the poor agreement noted earlier for the matrix cracking onset.

\section{CONCLUDING REMARKS}

A composite bonded skin/stringer specimen was used to demonstrate a methodology for determining the fatigue life based on matrix cracking and delamination fatigue onset characterization data along with geometric nonlinear finite element analyses. A consistent step-wise approach was used to investigate the damage mechanism in composite specimens which consisted of a tapered composite flange, representing a stringer or frame, bonded onto a composite skin. The approach used experiments to detect the failure mechanism, computational stress analysis to determine the location and onset of first matrix cracking, and computational fracture mechanics to investigate the potential for subsequent delamination growth.

In a first step, quasi-static tension and fatigue tests were performed to evaluate the debonding mechanisms between the skin and the bonded stringer. Specimen edges were examined on the microscope to document the damage occurrence. Observed failures initiated in the top $45^{\circ}$ skin ply near the flange tip causing the flange to almost fully debond from the skin.

Based upon the experimental findings, a two-dimensional nonlinear plane-stress finite element (FE) analysis was performed using the ABAQUS ${ }^{\mathbb{1}}$ FE code in a second step. To predict matrix cracking onset, the relationship between the externally applied tension load and the maximum principal stresses was determined through geometrically nonlinear analysis. Transverse tension fatigue life data from flexure tests of $90^{\circ}$ laminates loaded in three-point bending were used to generate an onset fatigue life P-N curve for matrix cracking. The resulting prediction agreed reasonably well with measured data from the skin/stringer specimen fatigue tests at higher cycles.

A fracture mechanics approach was used to determine when a delamination would grow from the transverse matrix cracks. Delaminations of various lengths were simulated as starting in 
locations where matrix cracks had been observed during the tests. Mixed mode energy release rates were computed using the virtual crack closure technique. It was demonstrated that the energy release rates and the corresponding mixed mode ratios, computed as a function of delamination length, were insensitive to small changes in the location used to start the initial matrix crack in the finite element model. Using the peak values in the mixed mode energy release rate versus delamination length plot, the relationship between the externally applied tension load and the critical energy release rate was created. Further, a failure surface relating the total energy release rate to the mixed mode ratio and the numbers of cycles to delamination onset was generated. The fit surface was used to create an onset fatigue life P-N curve for delamination at the computed mixed mode ratio. The resulting prediction was in good agreement with data from the skin/stringer specimen fatigue tests.

Additionally, the prediction curve for cumulative life to failure was generated from the matrix onset and delamination onset fatigue life curves. The results were in good agreement with data from the skin/stringer specimen fatigue tests which demonstrated that the methodology offers a significant potential to predict the cumulative fatigue life of composite structures.

\section{ACKNOWLEDGMENTS}

This work was performed as part of a Cooperative Research and Development Agreement (CRDA) between the U.S. Army Research Laboratory, Vehicle Technology Directorate, located at NASA Langley Research Center, and The Boeing Company, Philadelphia, PA. 


\section{REFERENCES}

I1] P. J. Minguet, M. J. Fedro, T. K. O'Brien, R. H. Martin, and L. B. Ilcewicz, "Development of a Structural Test Simulating Pressure Pillowing Effects in Bonded Skin/Stringer/Frame Configuration," in Proceedings of the Fourth NASA/DoD Advanced Composite Technology Conference, Salt Lake City, Utah, 1993.

[2] P. J. Minguet and T. K. O'Brien, "Analysis of Test Methods for Characterizing Skin/Stringer Debonding Failures in Reinforced Composite Panels," in Composite Materials: Testing and Design (Twelfth Volume), ASTM STP 1274, 1996, pp. 105--124.

|3| P. J. Minguet and T. K. O'Brien, "Analysis of Composite Skin/Stringer Bond Failures Using a Strain Energy Release Rate Approach," in The Tenth International Conference on Composite Materials, vol. I, A. Poursartip and K. Street, Eds., 1995, pp. 245--252.

14] P. J. Minguet, "Analysis of the Strength of the Interface Between Frame and Skin in a Bonded Composite Fuselage Panel," in The 38rd AIAA/ASME/ASCE/AHS/ASC Structures, Structural Dynamics and Materials Conference, 1997, pp. 2783--2790.

I5] M. K. Cvitkovich, T. K. O'Brien, and P. J. Minguet, "Fatigue Debonding Characterization in Composite Skin/Stringer Configurations," in Composite Materials: Fatigue and Fracture, Seventh Volume, ASTM STP 1330: American Society for Testing and Materials, 1998, pp. 97-121.

|6| R. Krueger, M. K. Cvitkovich, T. K. O'Brien, and P. J. Minguet, "Testing and Analysis of Composite Skin/Stringer Debonding Under Multi-Axial Loading," Journal of Composite Materials, vol. 34, pp. 1263-1300, 2000.

I7I G. B. Murri, T. K. O'Brien, and C. Q. Rousseau, "Fatigue Life Methodology for Tapered Composite Flexbeam Laminates," Journal of the American Helicopter Society, vol. 43, pp. 146--155, 1998.

[8] ABAQUS/Standard - User's Manual - Version 5.6, vol. II: Hibbitt, Karlsson \& Sorensen, Inc., 1996.

191 D. M. Hoyt, S. H. Ward, and P. J. Minguet, "Strength and Fatigue Life Modeling of Bonded Joints in Composite Structure," in Proceedings of the American Society for Composites - 15th Annual Technical Conference on Composite Materials: Technomic Publishing. 2000, pp. 729-736.

[10] E. F. Rybicki and M. F. Kanninen, "A Finite Element Calculation of Stress Intensity Factors by a Modified Crack Closure Integral," Eng. Fracture Mech., vol. 9, pp. 931--938, 1977. 
[11] I. S. Raju, "Calculation Of Strain-Energy Release Rates With Higher Order And Singular Finite Elements," Eng. Fracture Mech., vol. 28, pp. 251--274, 1987.

[12] I. S. Raju, J. H. Crews, and M. A. Aminpour, "Convergence of Strain Energy Release Rate Components for Edge-Delaminated Composite Laminates," Eng. Fracture Mech., vol. 30, pp. 383--396, 1988.

[13] C. T. Sun and M. G. Manoharan, "Strain Energy Release Rates of an Interfacial Crack Between Two Orthotropic Solids," J. Composite Materials, vol. 23, pp. 460--478, 1989.

114] A. A. Johnston, "An Integrated Model of the Development of Process-Induced Deformation in Autoclave Processing of Composite Structures," Ph.D. Thesis, The University of British Columbia, Vancouver, B.C., Canada, 1997.

[15] R. H. Martin, "Incorporating interlaminar fracture mechanics into design," in International Conference on Designing Cost-Effective Composites: IMechE Conference Transactions, London, U.K., 1998, pp. 83-92.

[16] P. Hansen and R. Martin, "DCB, 4ENF and MMB Delamination Characterisation of S2/8552 and IM7/8552," Materials Engineering Research Laboratory Ltd. (MERL), Hertford, U.K., N68171-98-M-5177, 1999. 
TABLE 1. MATERIAL PROPERTIES

\begin{tabular}{|c|c|c|}
\hline \multicolumn{3}{|c|}{ IM7/8552 Unidirectional Graphite/Epoxy Prepreg } \\
\hline$E_{11}=161.0 \mathrm{GPa}$ & $E_{22}=11.38 \mathrm{GPa}$ & $E_{33}=11.38 \mathrm{GPa}$ \\
\hline$v_{12}=0.32$ & $v_{13}=0.32$ & $v_{23}=0.45$ \\
\hline$G_{12}=5.17 \mathrm{GPa}$ & $G_{13}=5.17 \mathrm{GPa}$ & $G_{23}=3.92 \mathrm{GPa}$ \\
\hline \multicolumn{3}{|c|}{ IM7/8552 Graphite/Epoxy Plain Weave Fabric } \\
\hline$E_{11}=71.7 \mathrm{GPa}$ & $E_{22}=71.7 \mathrm{GPa}$ & $E_{33}=10.3 \mathrm{GPa}$ \\
\hline$v_{12}=0.04$ & $v_{13}=0.35$ & $123=0.35$ \\
\hline$G_{12}=4.48 \mathrm{GPa}$ & $G_{13}=4.14 \mathrm{GPa}$ & $G_{23}=4.14 \mathrm{GPa}$ \\
\hline \multicolumn{3}{|c|}{ Grade 5 FM 300 Adhesive } \\
\hline$E=1.72 \mathrm{GPa}$ & $v=0.3$ & (assumed isotropic) \\
\hline
\end{tabular}




\section{APPENDIX}

Currently, the large commercial finite element codes do not offer the choice for calculating the mixed mode energy release rates using the virtual crack closure technique (VCCT) as described in the main text. Therefore, the energy release rate components $G_{1}$ and $G_{11}$ were computed in an separate post-processing step. The element forces at nodes, the nodal point displacements and the nodal point coordinates required as input were extracted directly from the ABAQUS ${ }^{\text {di }}$ binary result

file using a user written FORTRAN routine (extract.f) the flow chart of which is depicted in Figure 31 . 

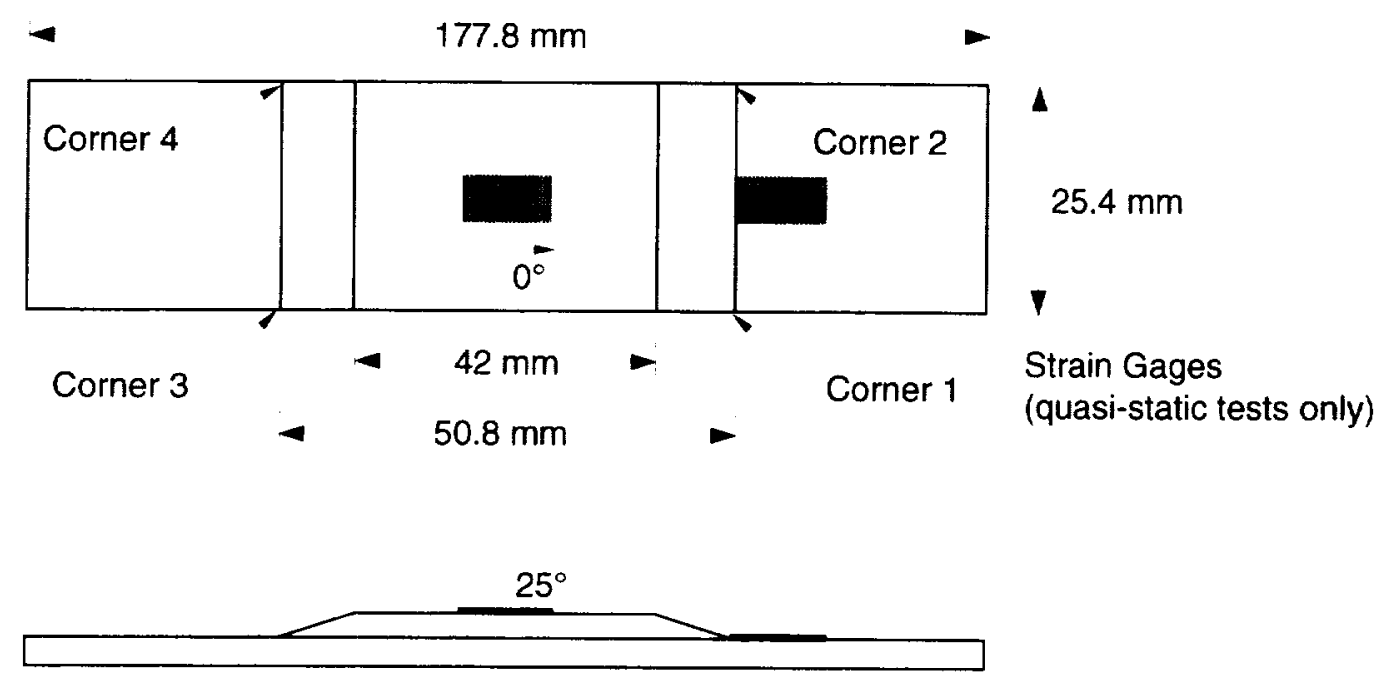

Figure 1. Specimen Configuration.

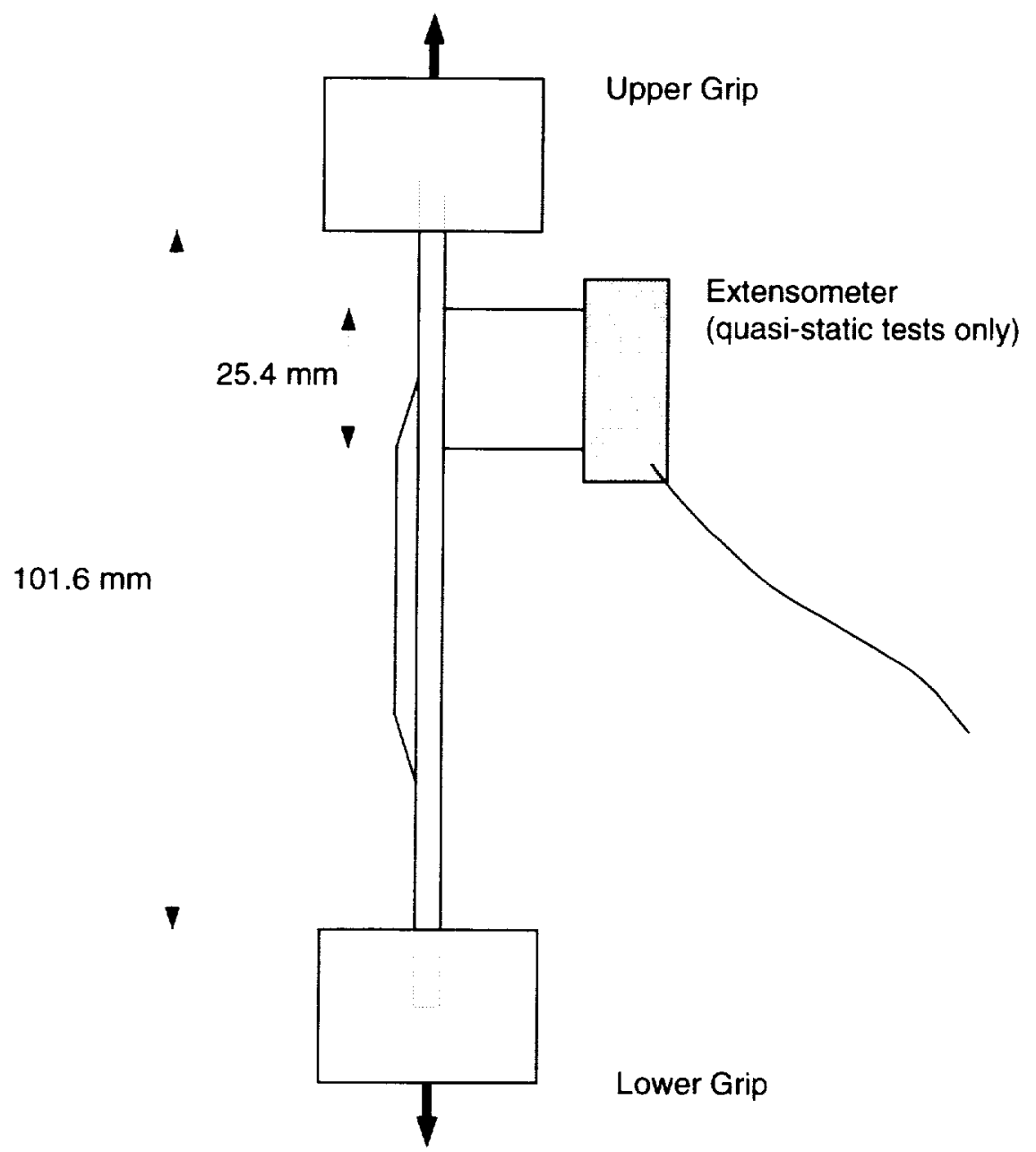

Figure 2. Tension Test Set-Up. 


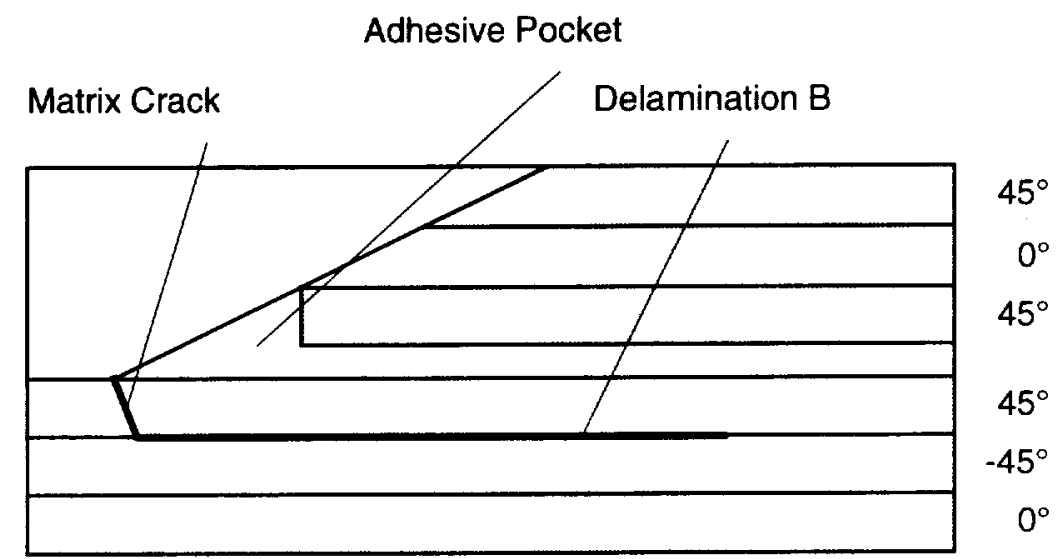

(a) Typical damage pattern

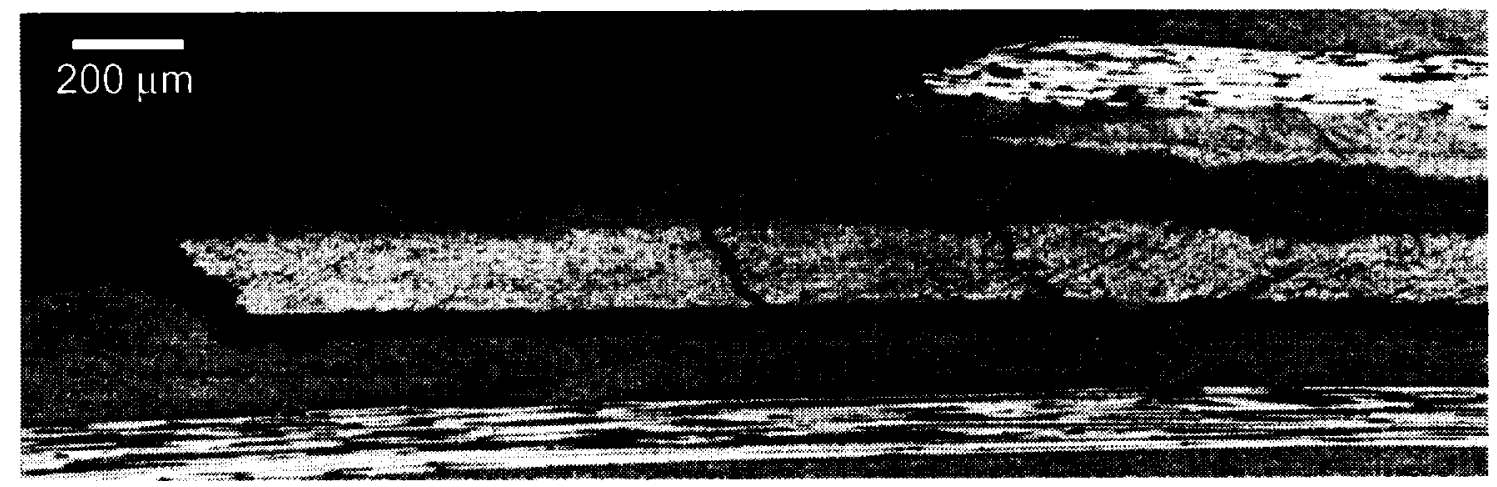

(b) Micrograph of the edge of a failed specimen.

Figure 3. Damage patterns at corners 2 and 3. 
Flange tip

Adhesive layer

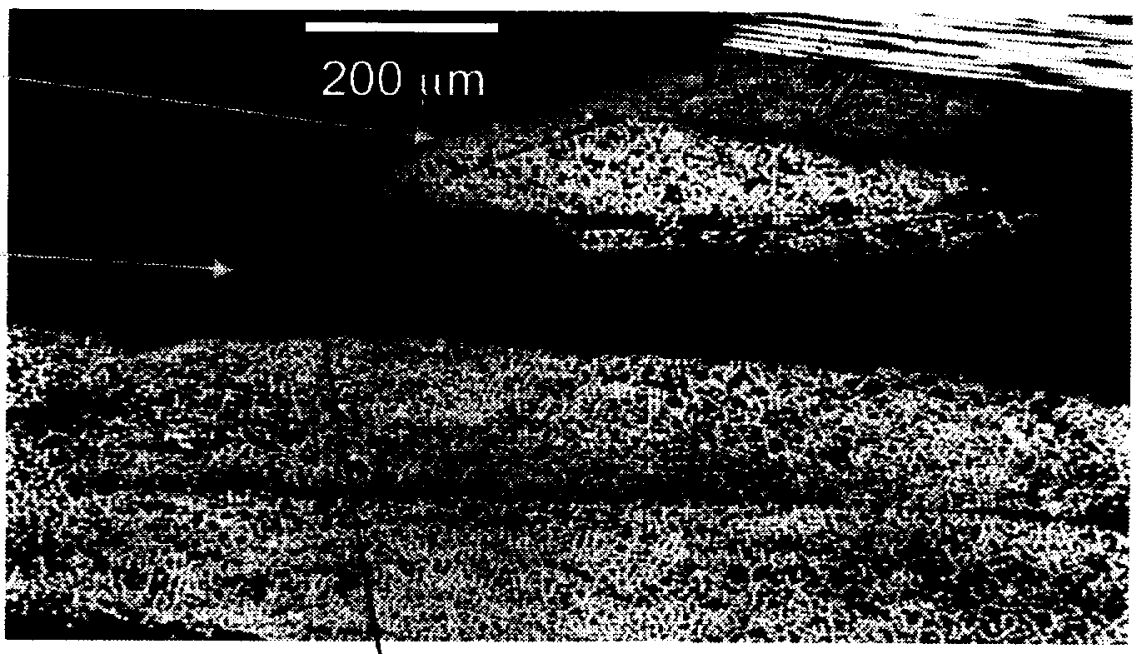

Matrix crack in top $45^{\circ}$ ply

Second matrix crack Initial matrix crack closed Initial crack in adhesive layer

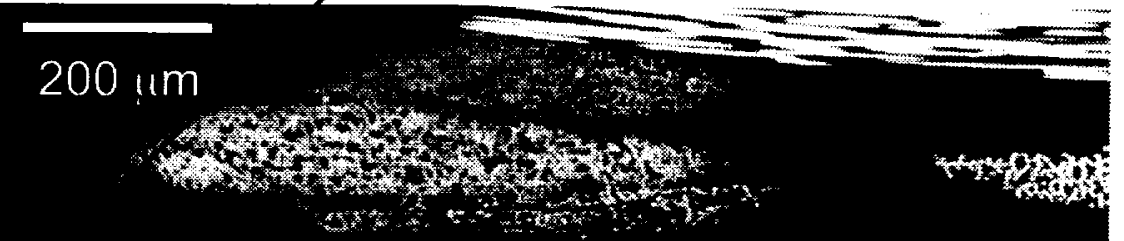

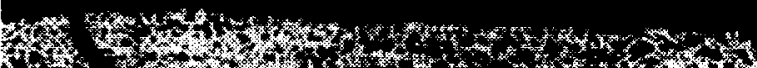

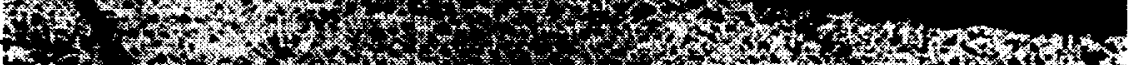
Now

\section{(}

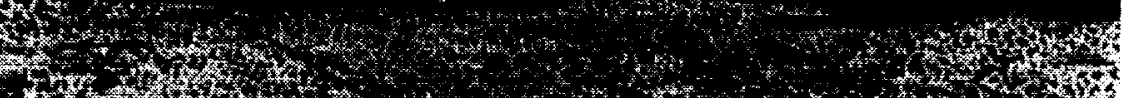
196. (1)

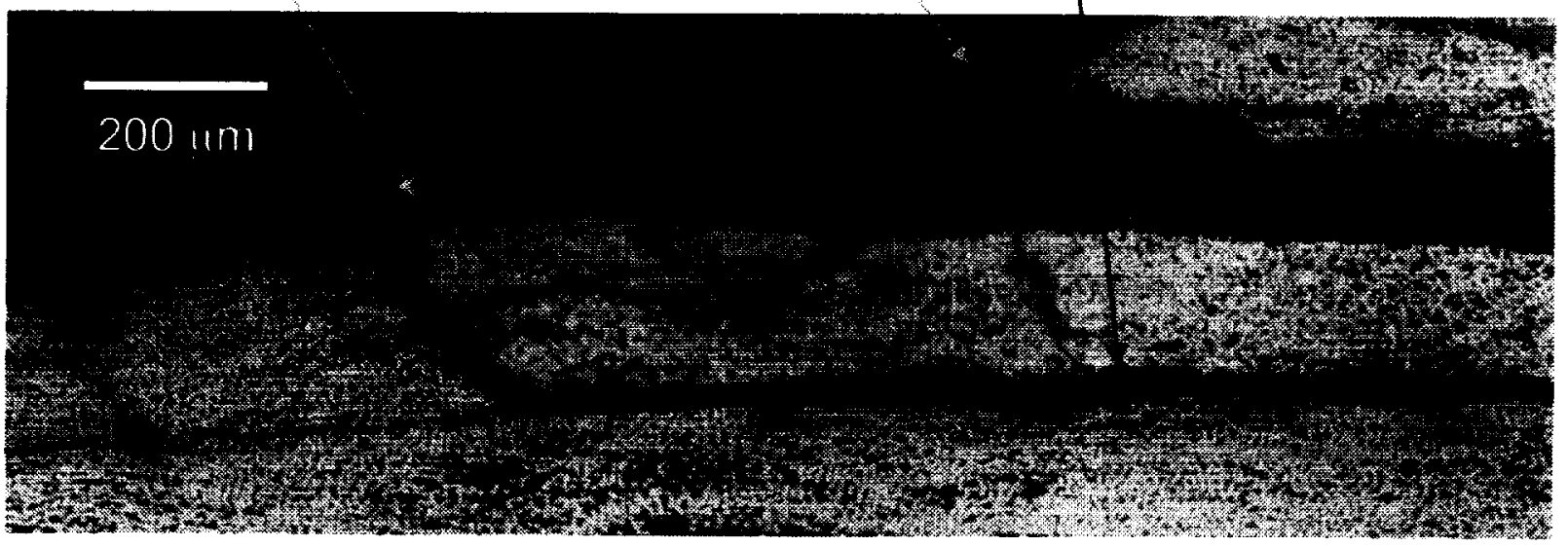

Figure 4. Evolution of matrix cracks and delamination growth in fatigue, corners 2 and 3. 


\section{Delamination $\mathrm{A} 1$}

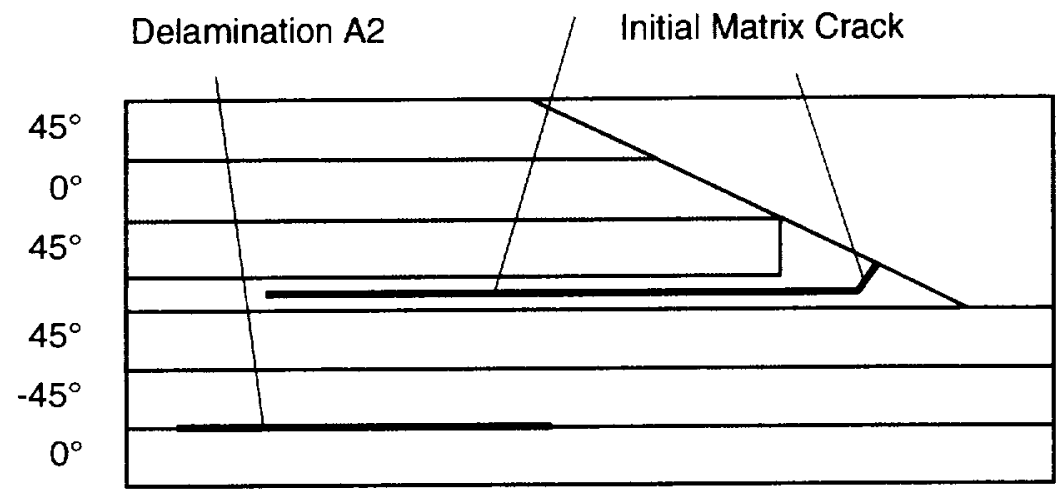

(a) Typical damage pattern.

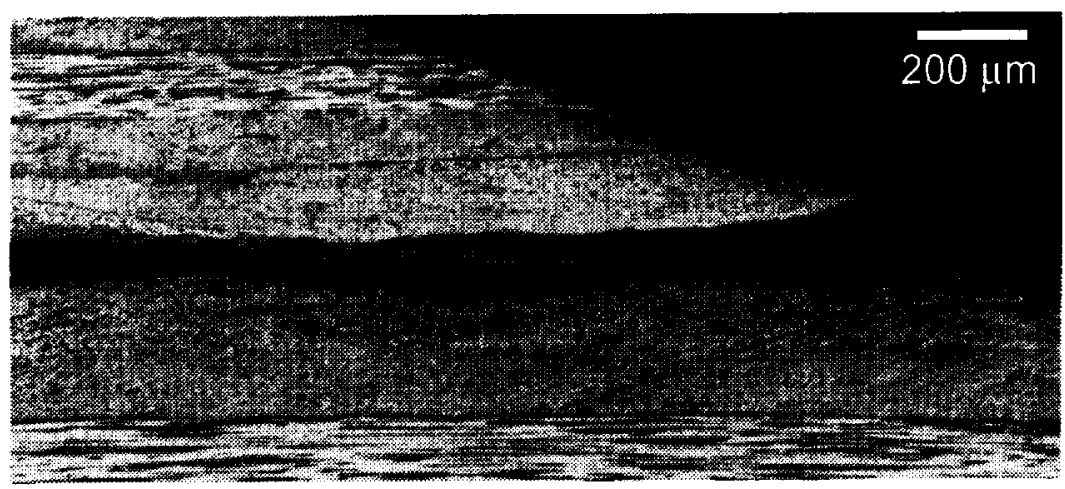

(b) Micrograph of the edge of a failed specimen.

Figure 5. Damage patterns at corner 1 and 4. 


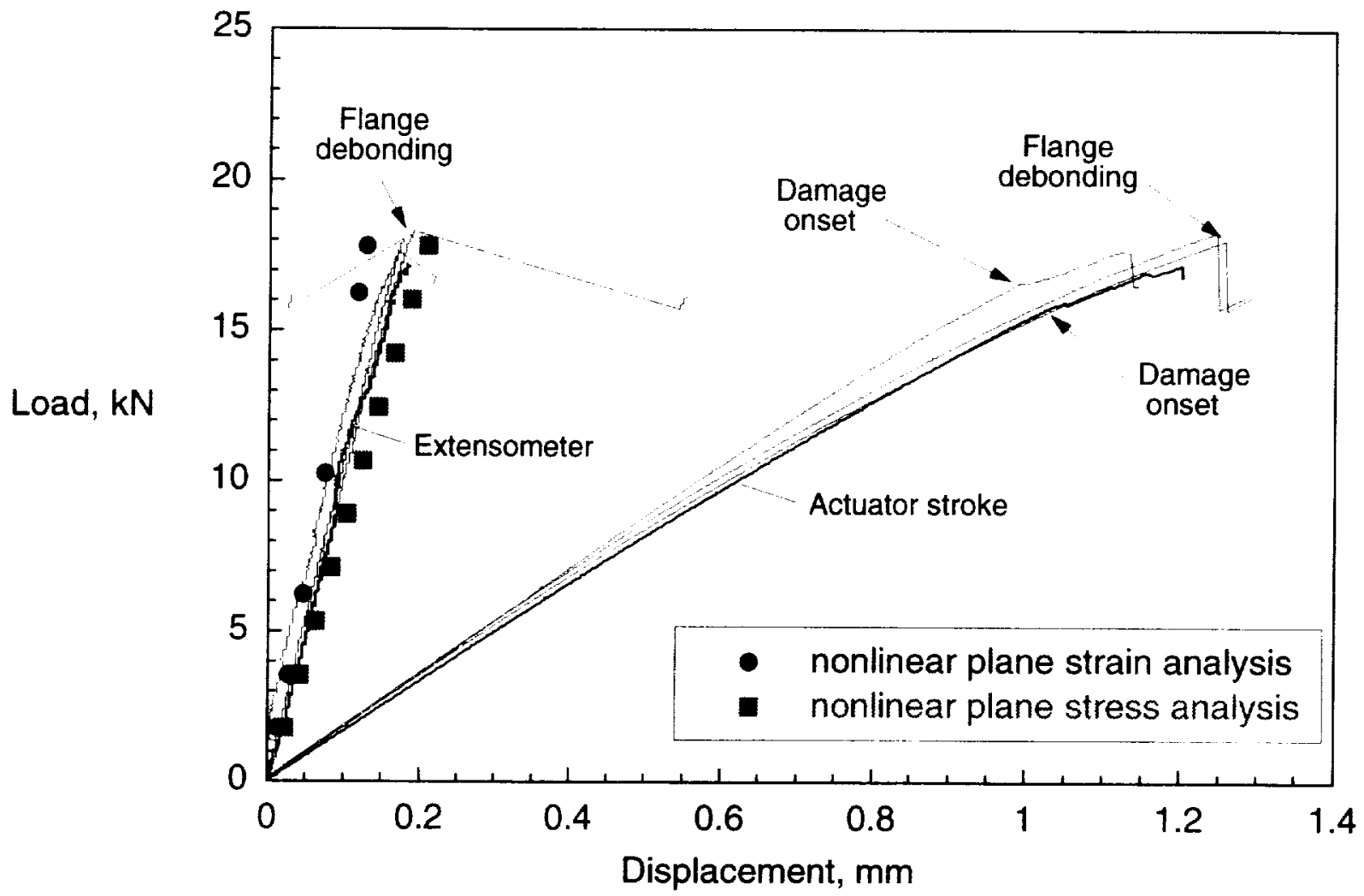

Figure 6. Load-displacement plots for quasi-static tests.

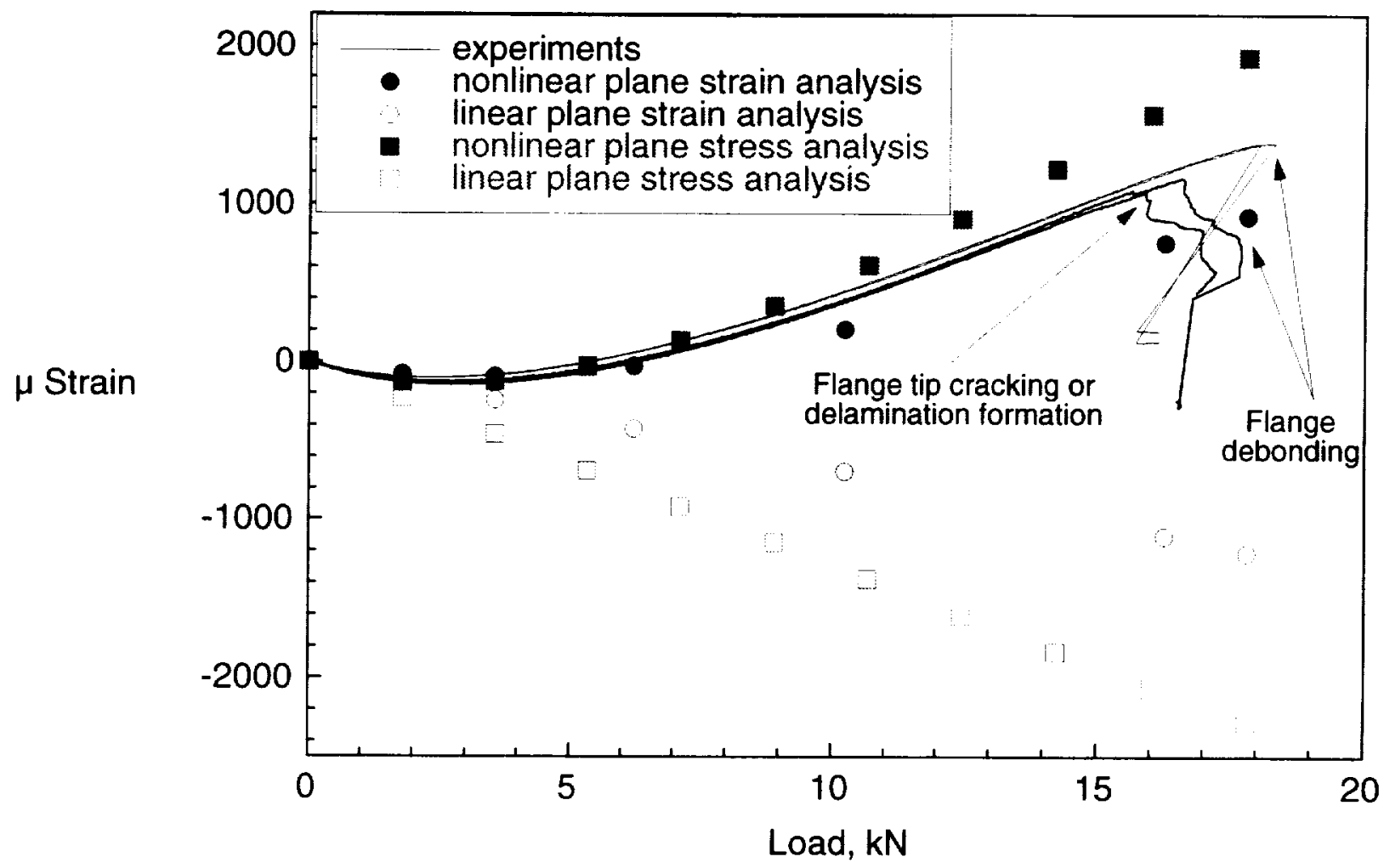

Figure 7. Flange strain-load plots for quasi-static tests. 


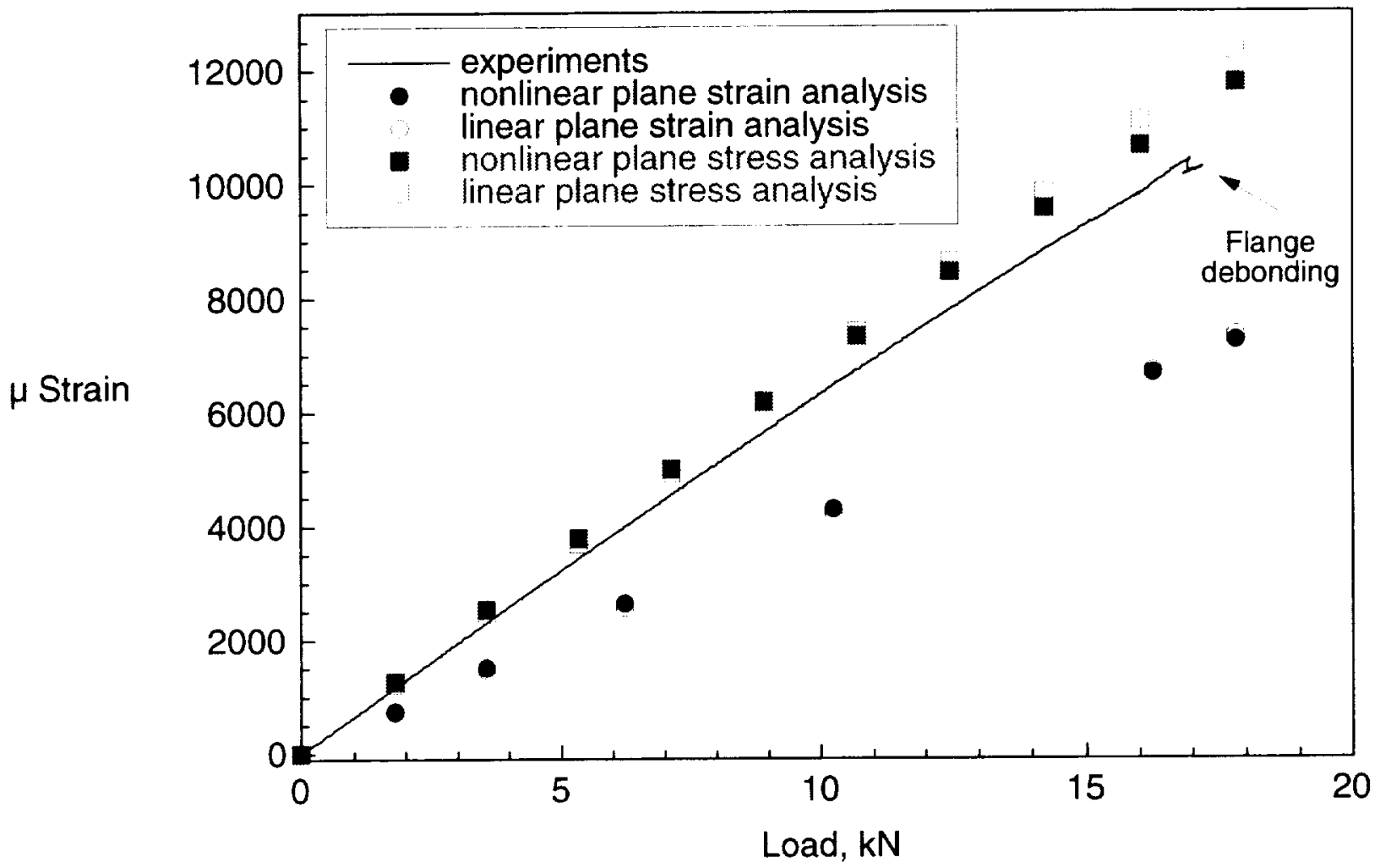

Figure 8. Typical skin strain-load plot for quasi-static tests.

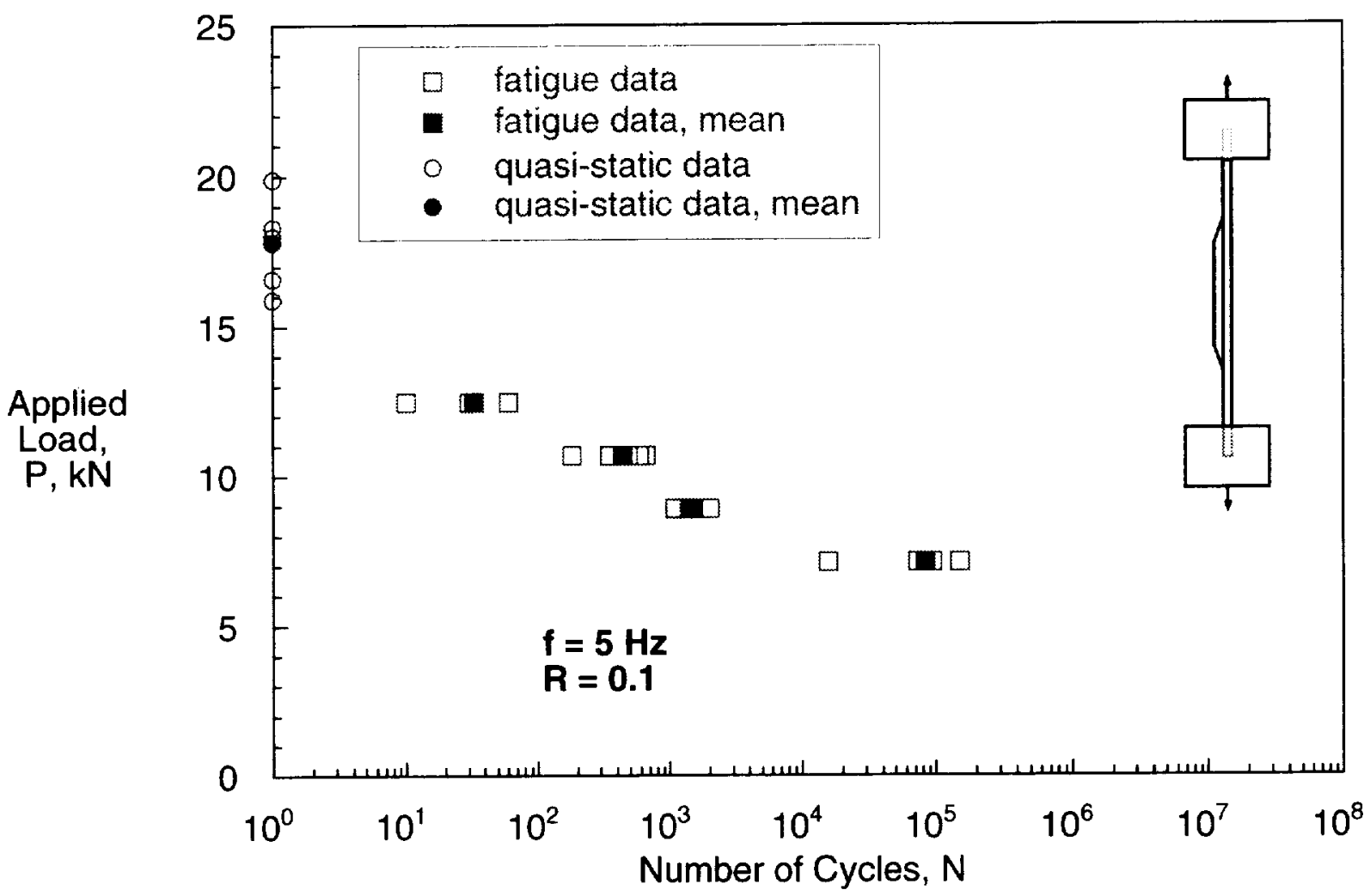

Figure 9. Matrix crack onset fatigue life for composite skin/flange debonding 


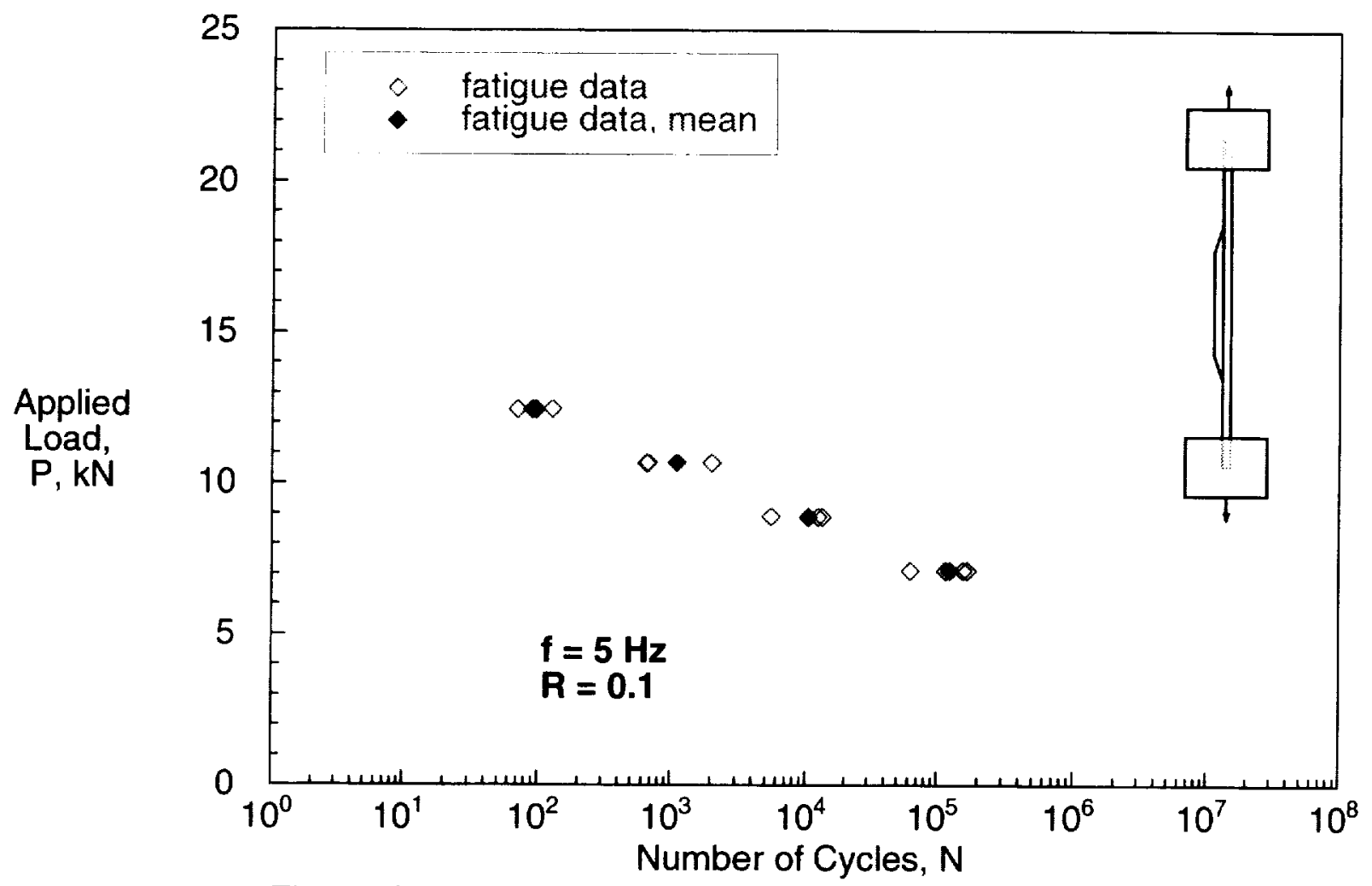

Figure 10. Delamination onset fatigue life following matrix cracking for composite skin/flange debonding

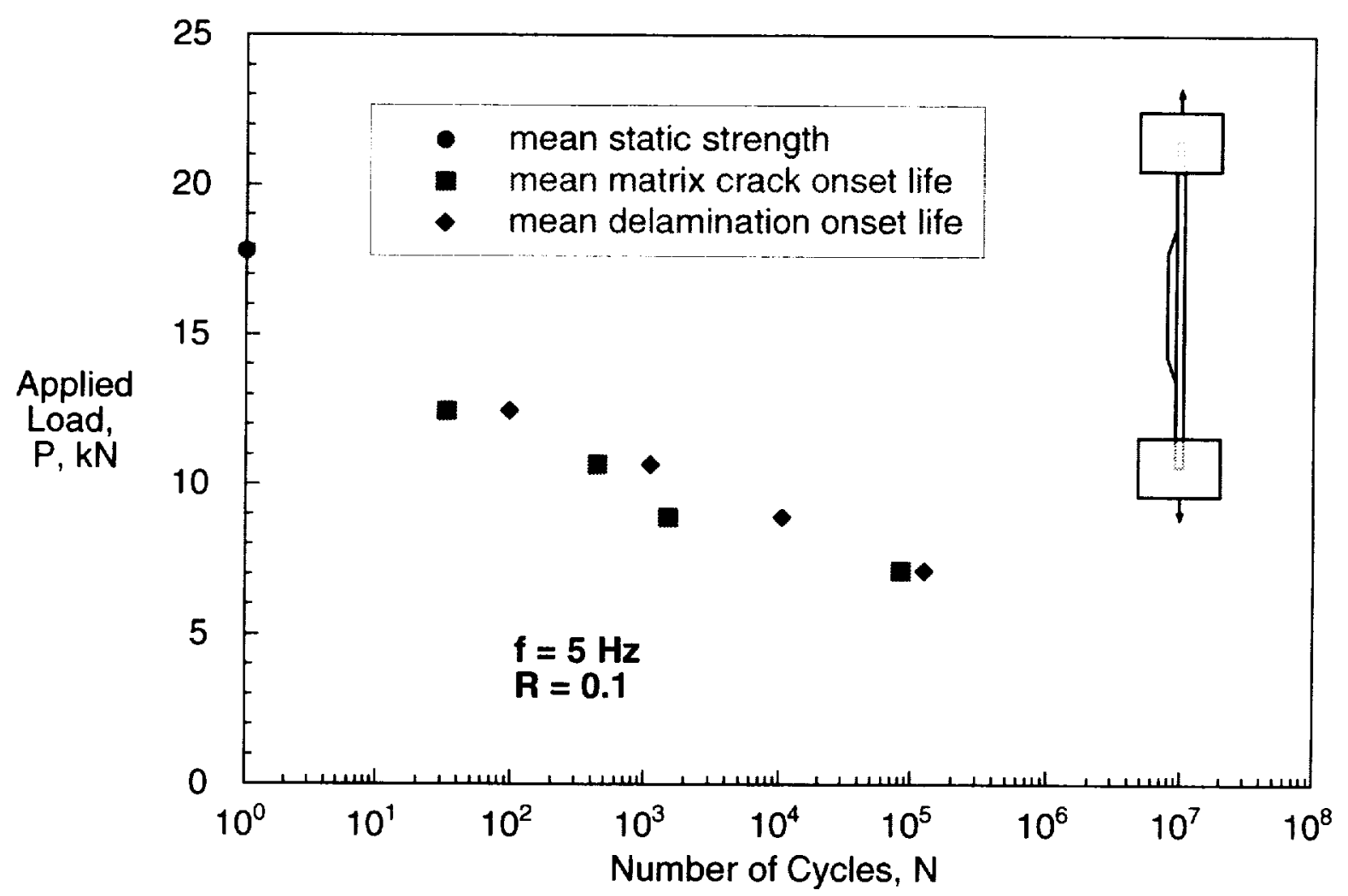

Figure 11. Fatigue life for composite skin/flange debonding. 

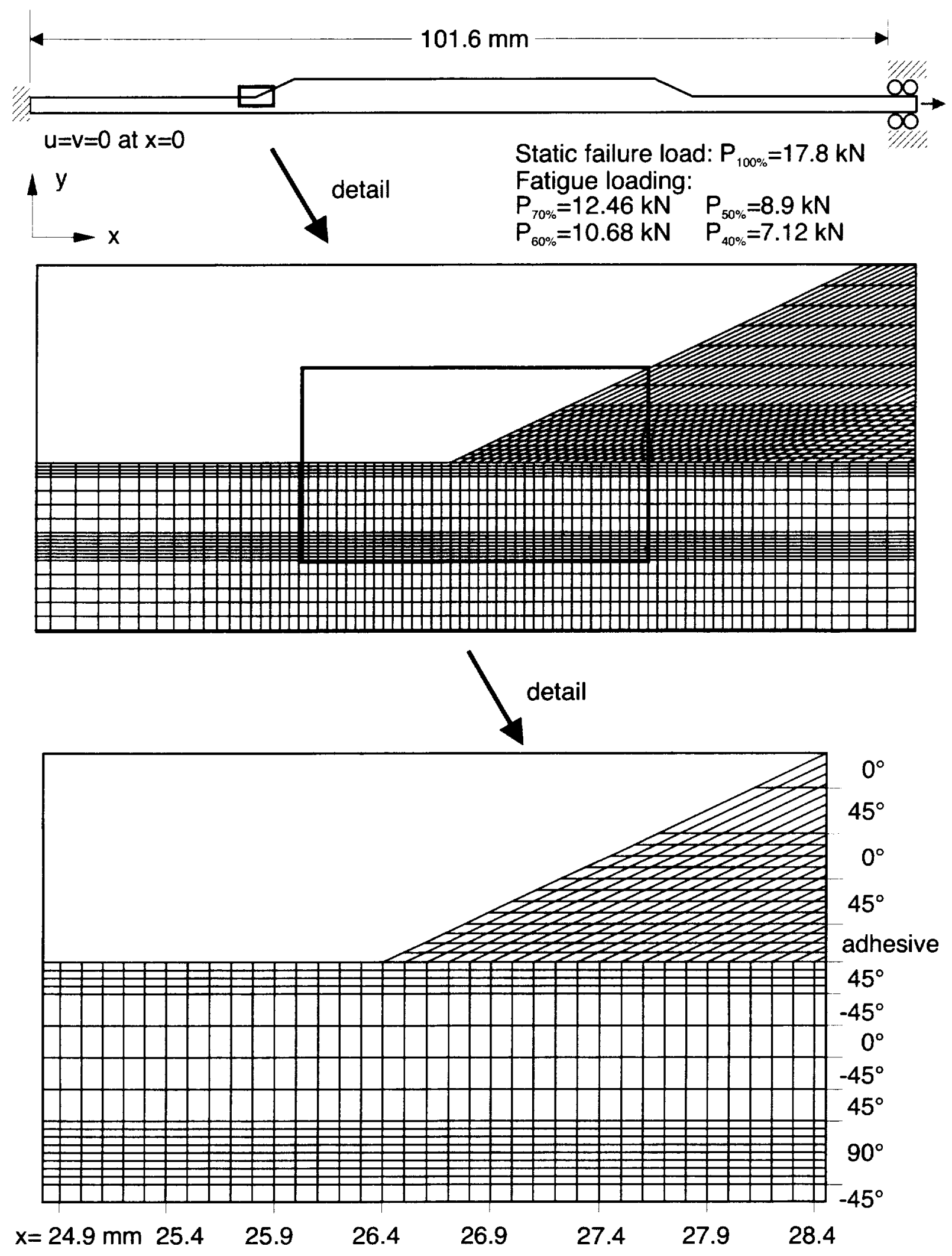

Figure 12. Finite element model of skin/flange specimen 


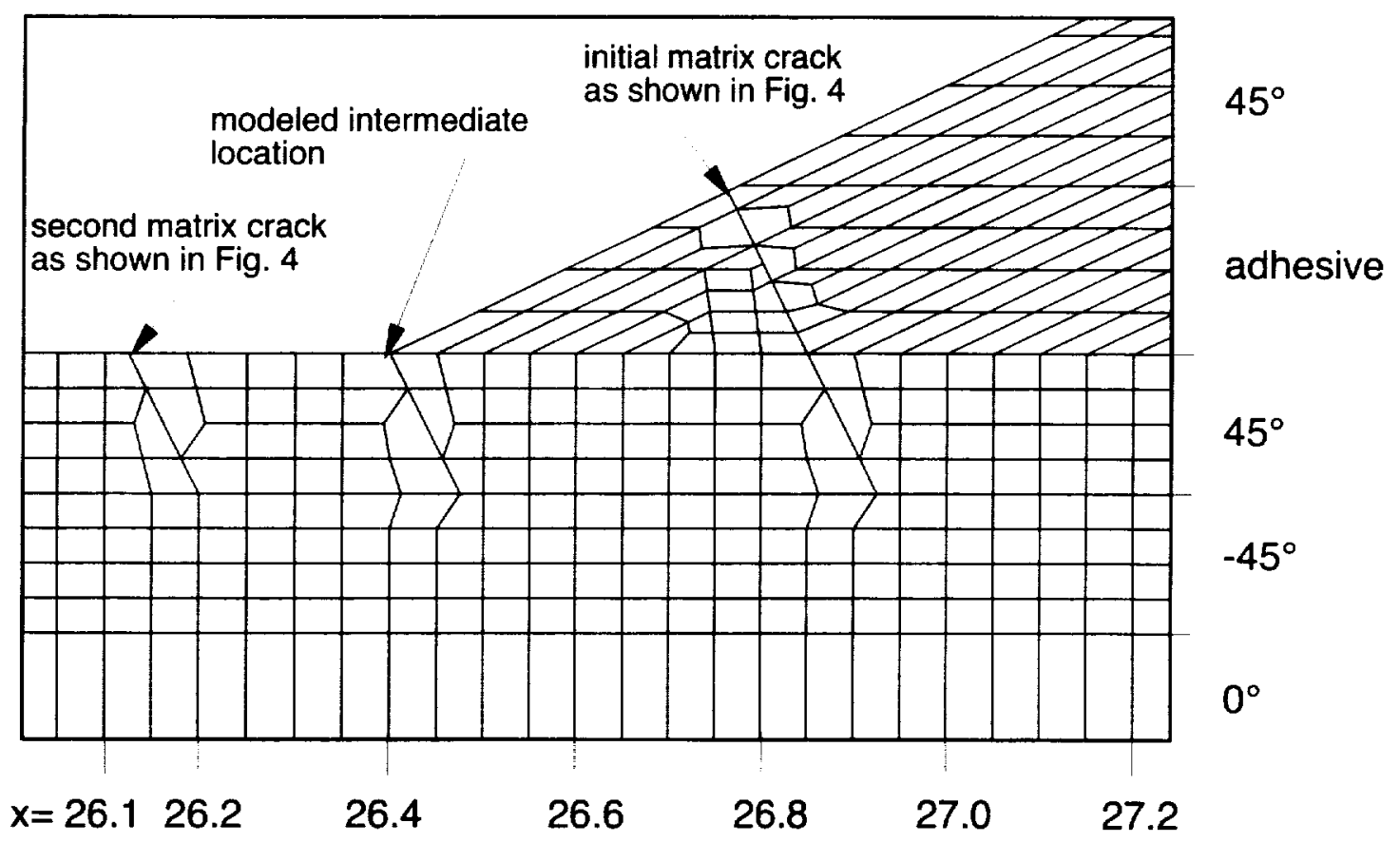

(a) Model used to simulate different damage onset locations

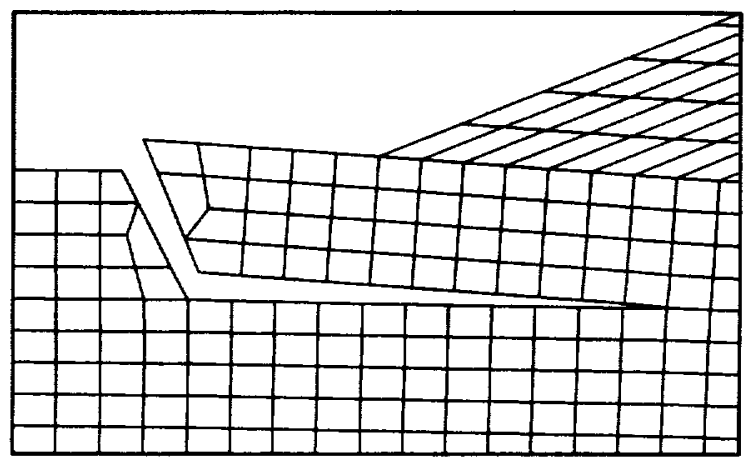

(b) Delamination B growing from second matrix crack

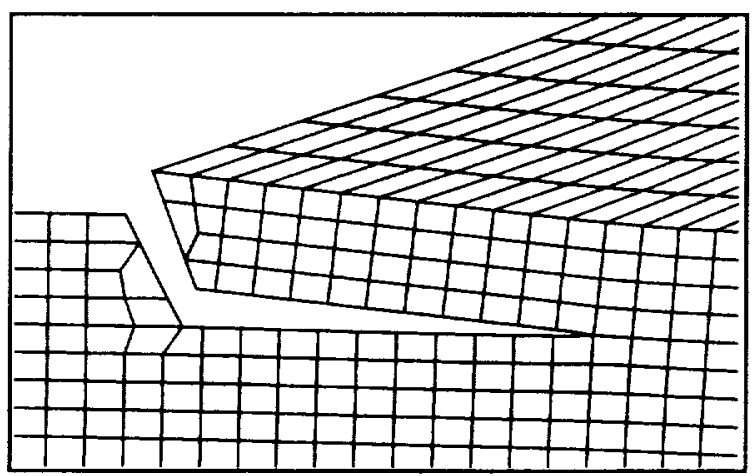

(c) Delamination B growing from intermediate location of matrix crack

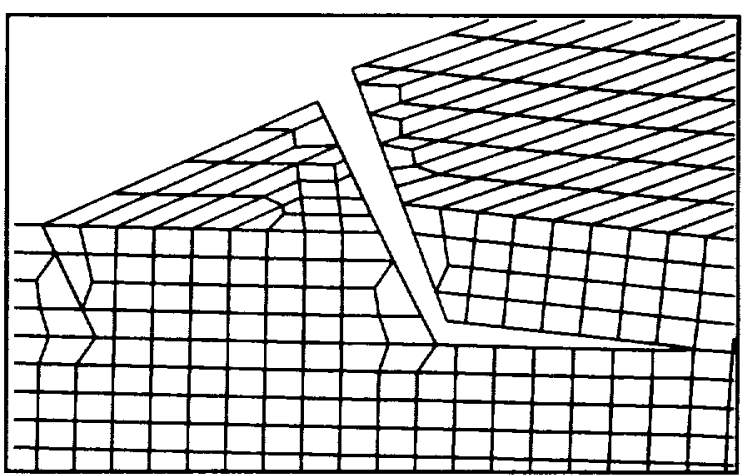

(d) Delamination $\mathrm{B}$ growing from initial first matrix crack

Figure 13. Finite element model of damaged zone around flange tip 


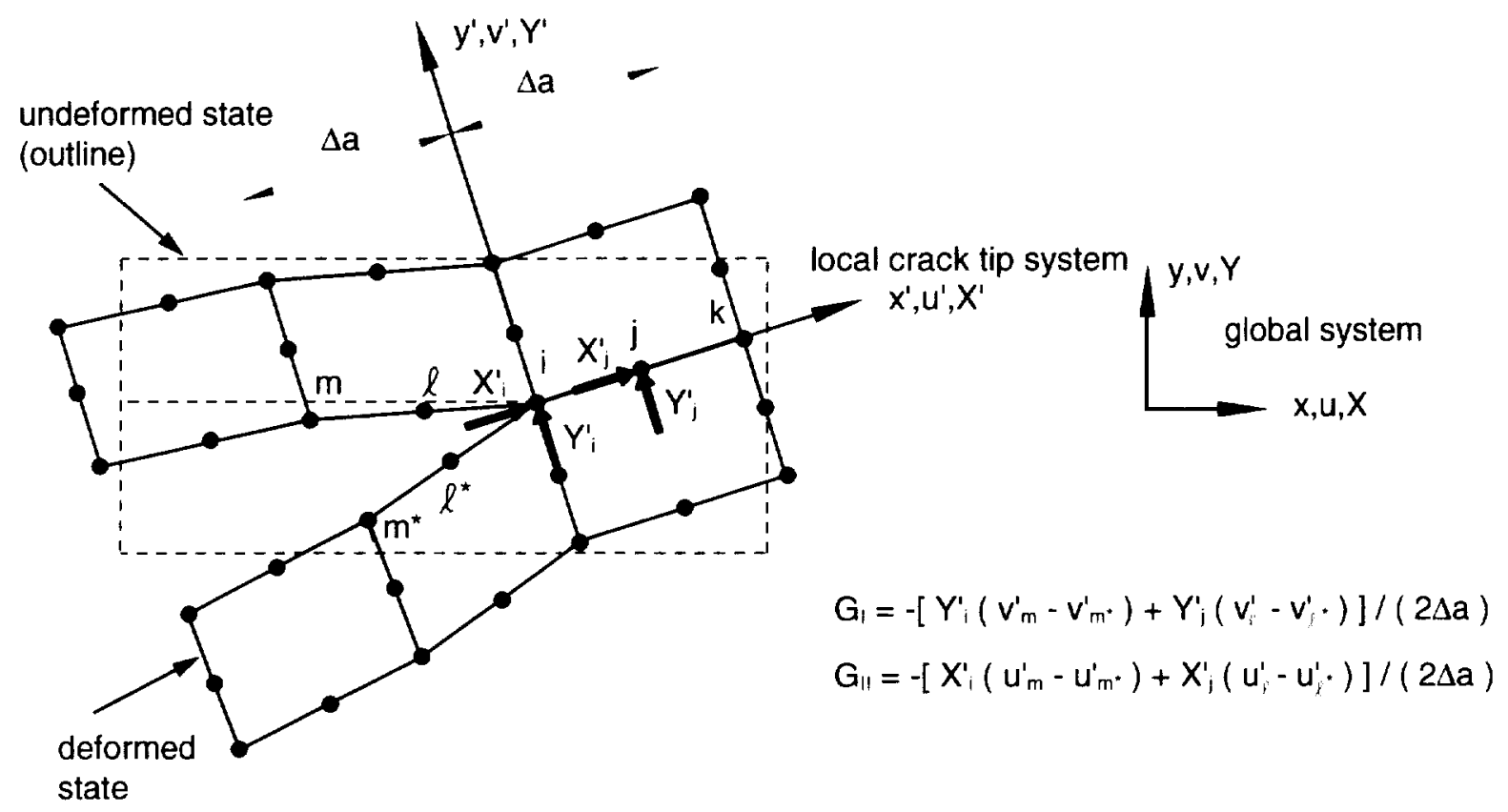

Figure 14. Virtual Crack Closure Technique (VCCT). 


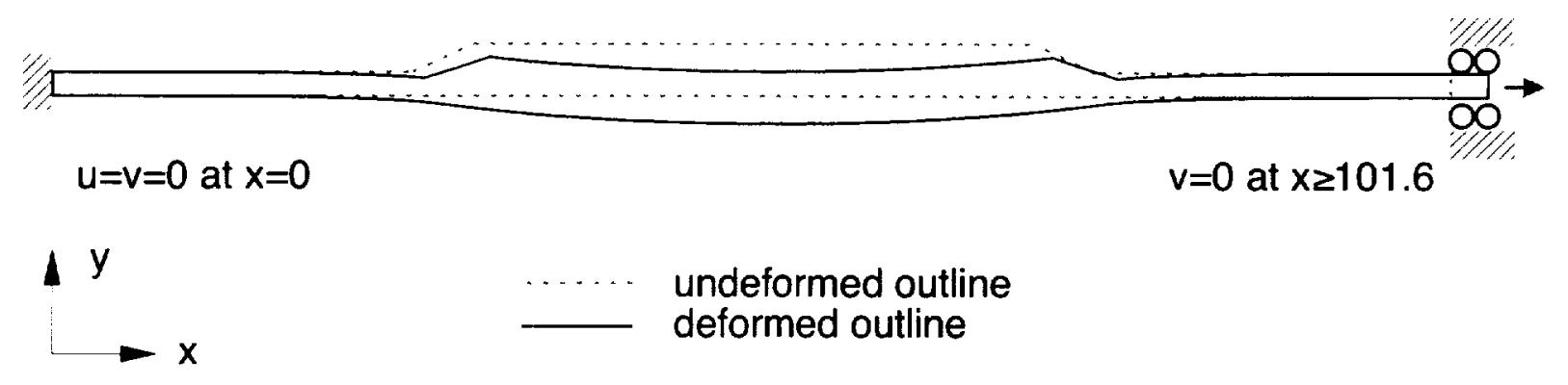

Figure 15. Deformed outline of modeled skin/flange specimen 


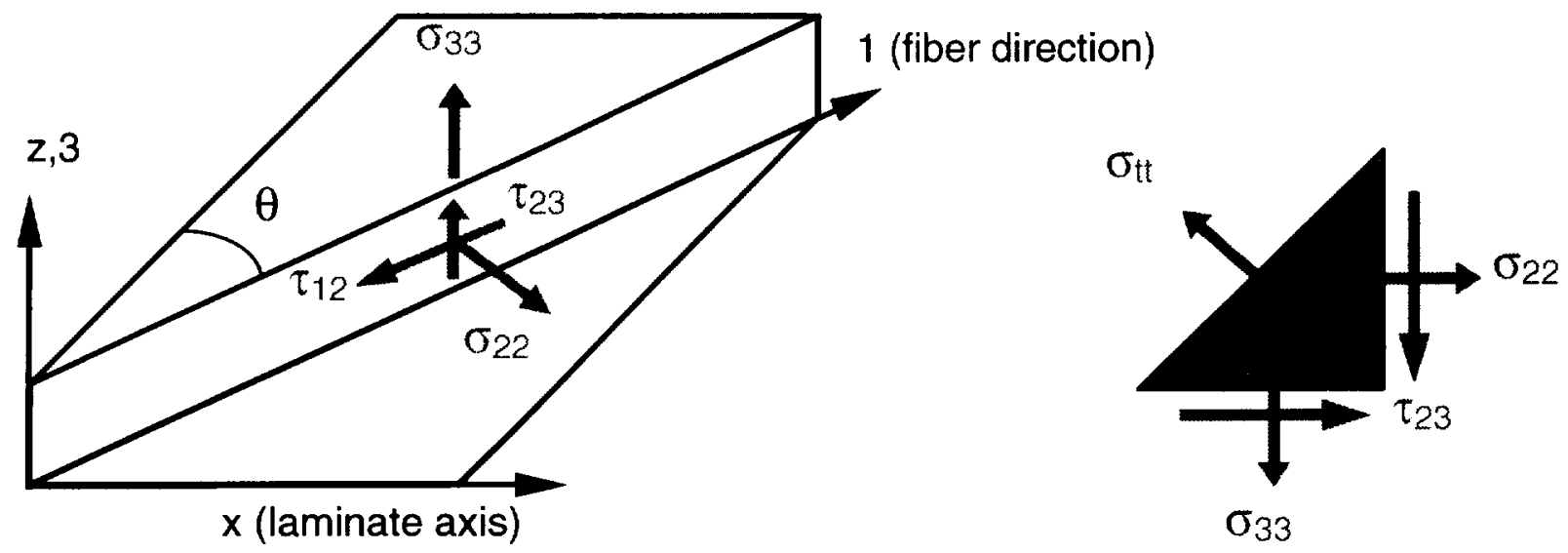

Figure 16. Definition of ply transverse tensile stress. 


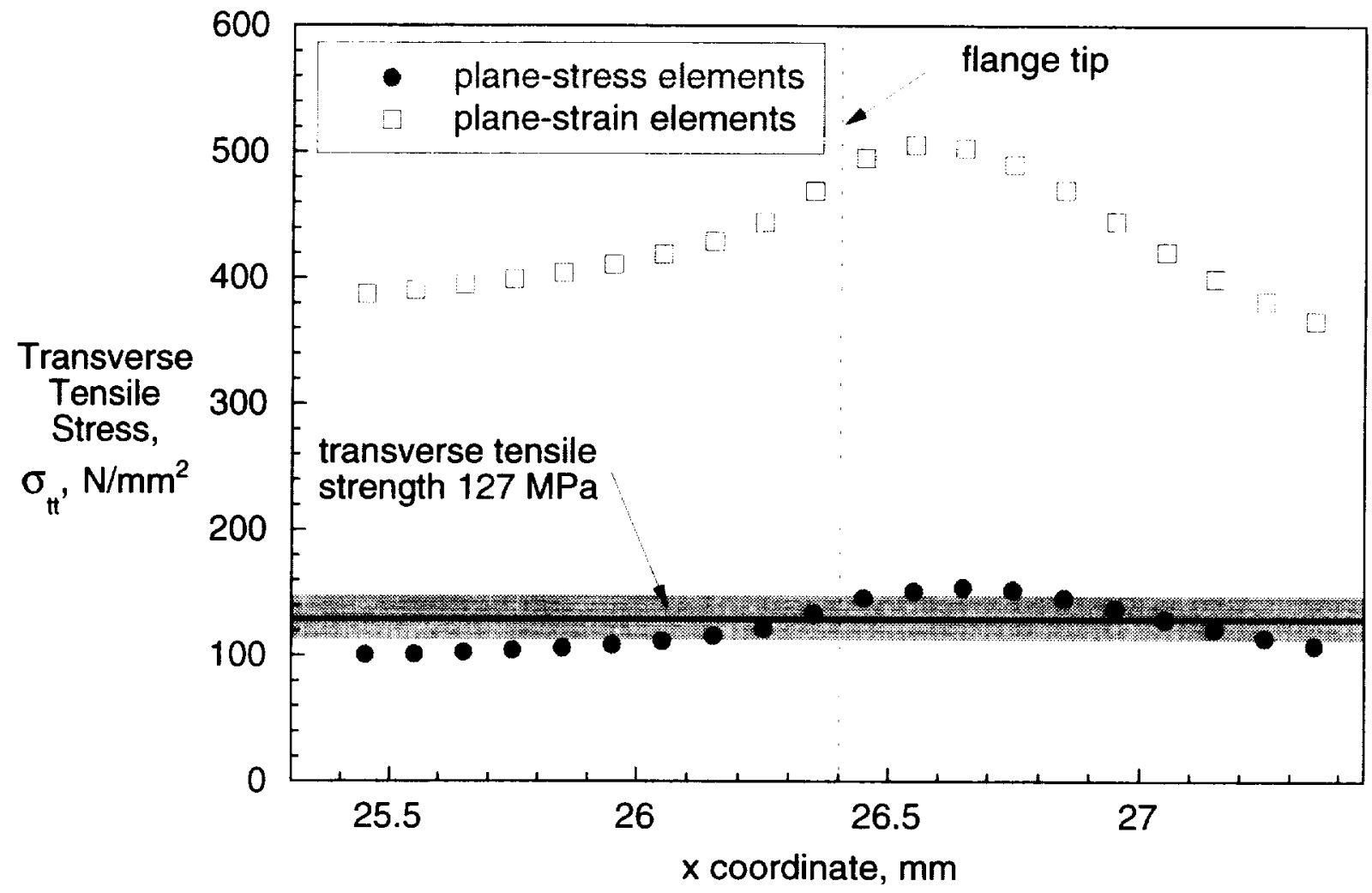

Figure 17. Computed transverse tensile stress results in top $45^{\circ}$ skin ply for static failure load.

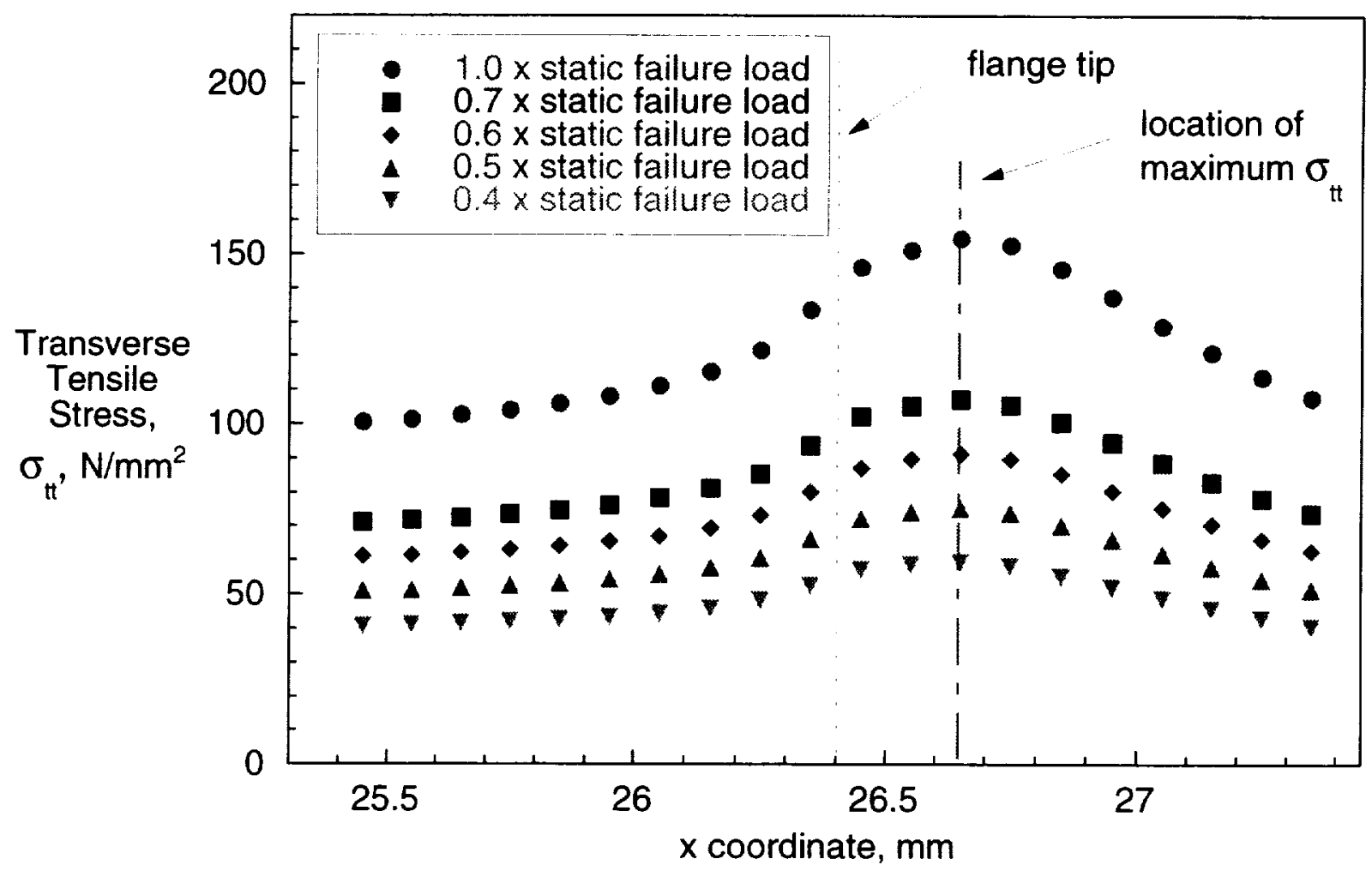

Figure 18. Computed transverse tensile stress results in top $45^{\circ}$ skin ply for fatigue loads. 


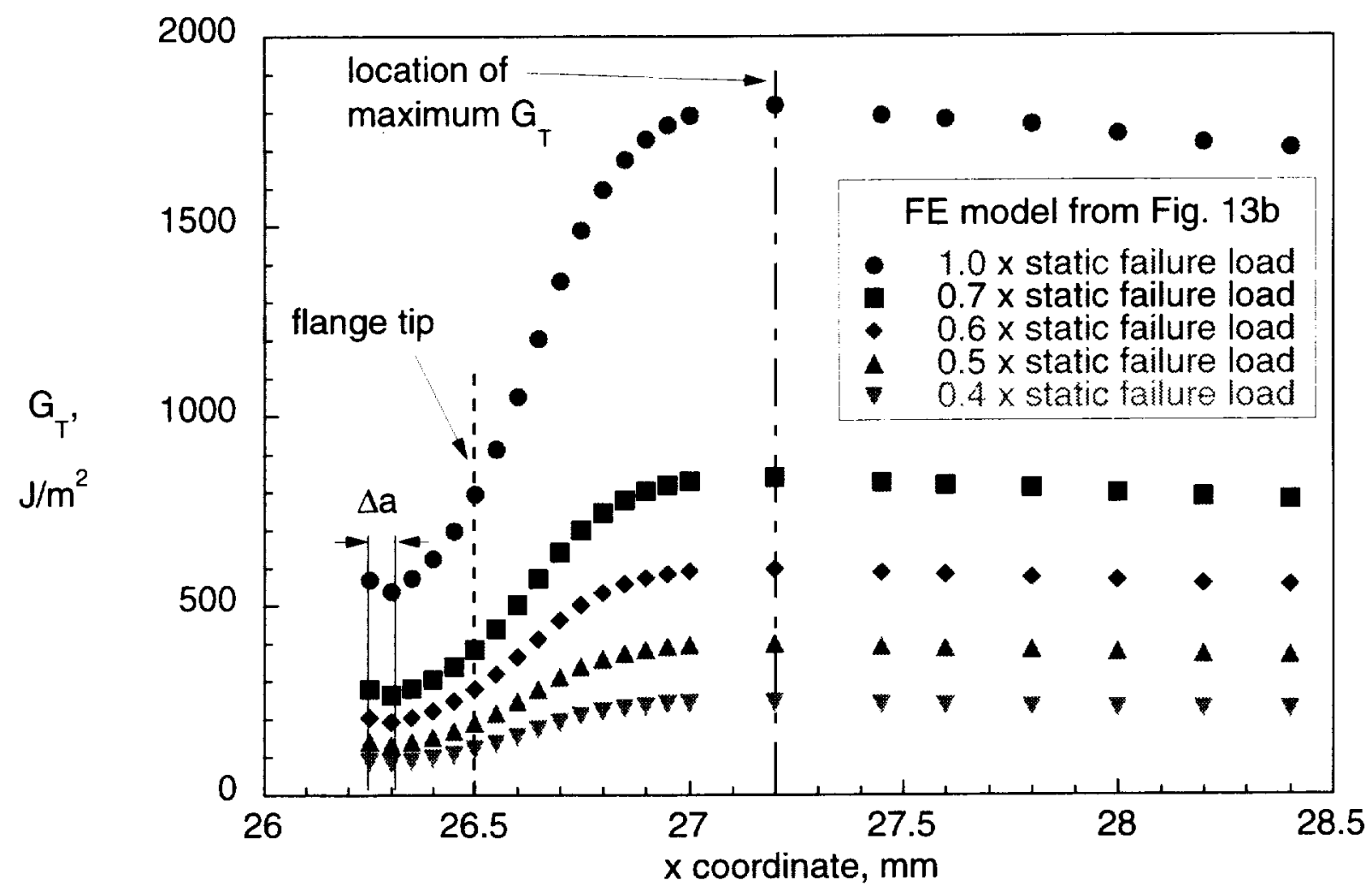

Figure 19. Computed total strain energy release rate for delamination between top $45^{\circ} /-45^{\circ}$ skin plies.

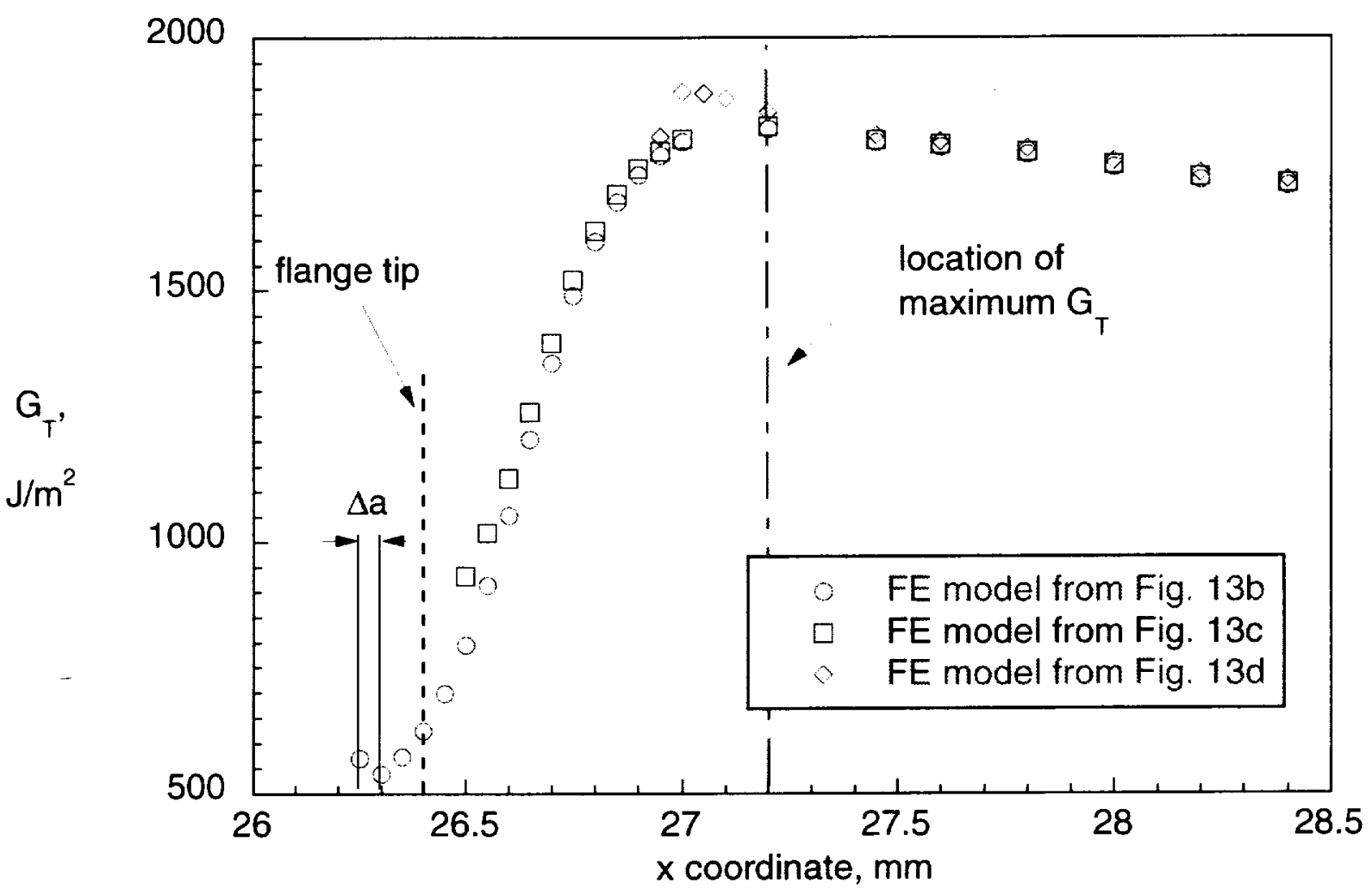

Figure 20. Computed total strain energy release rate for delamination between top $45^{\circ} /-45^{\circ}$ skin plies. 


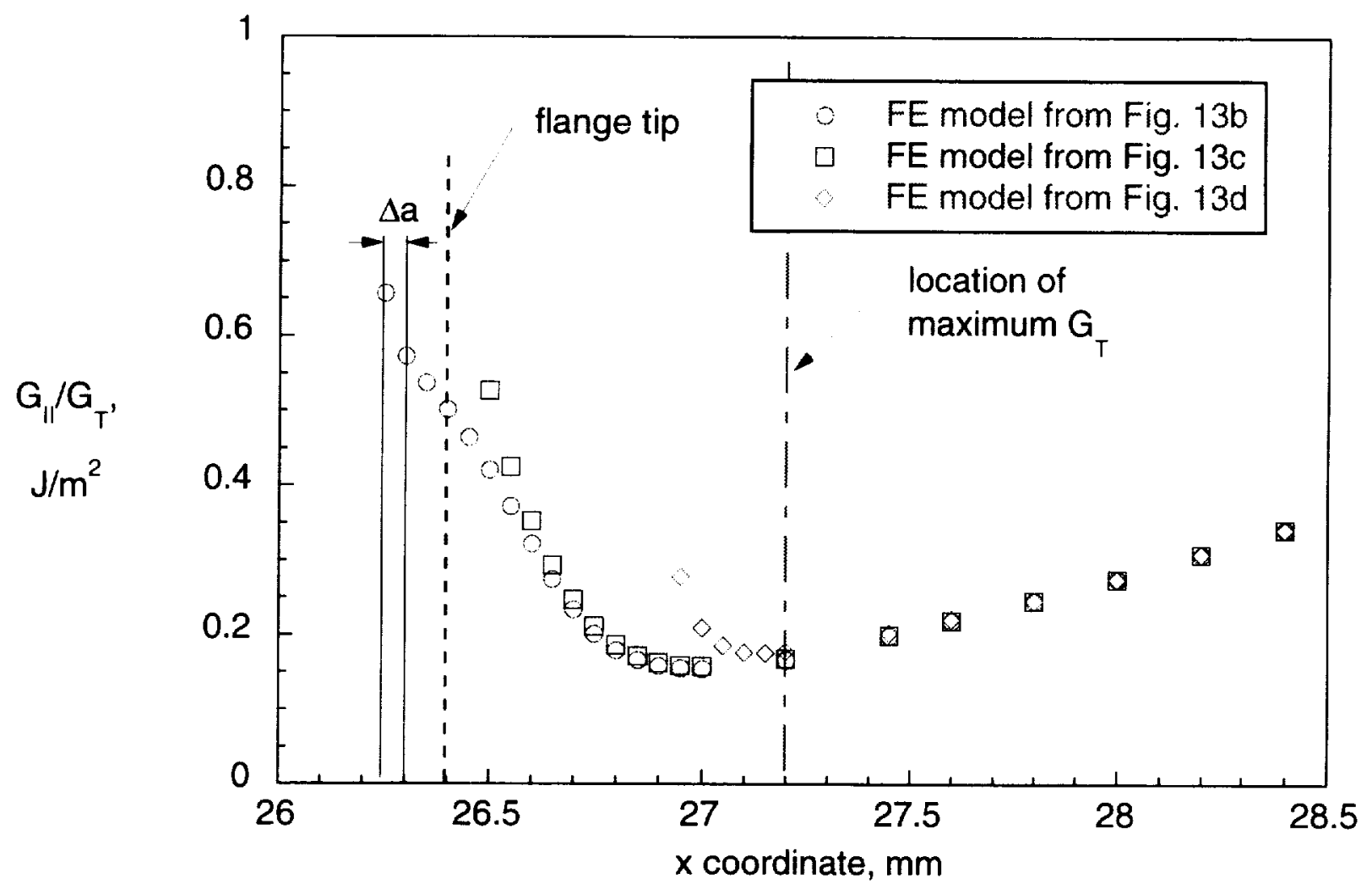

Figure 21. Computed mixed mode ratio for delamination between top $45^{\circ} / 45^{\circ}$ skin plies.

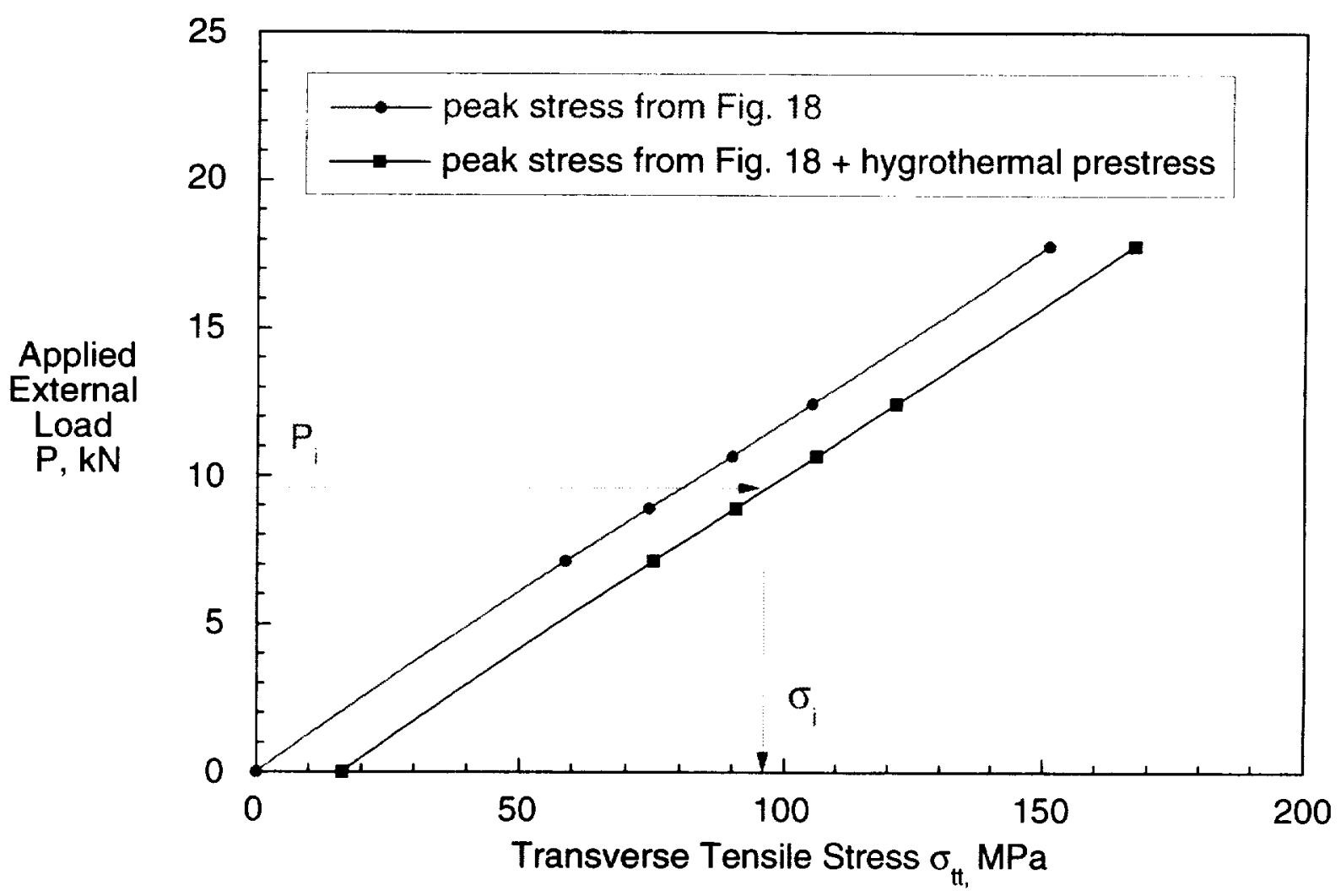

Figure 22. External load versus calculated ply transverse tensile stress. 


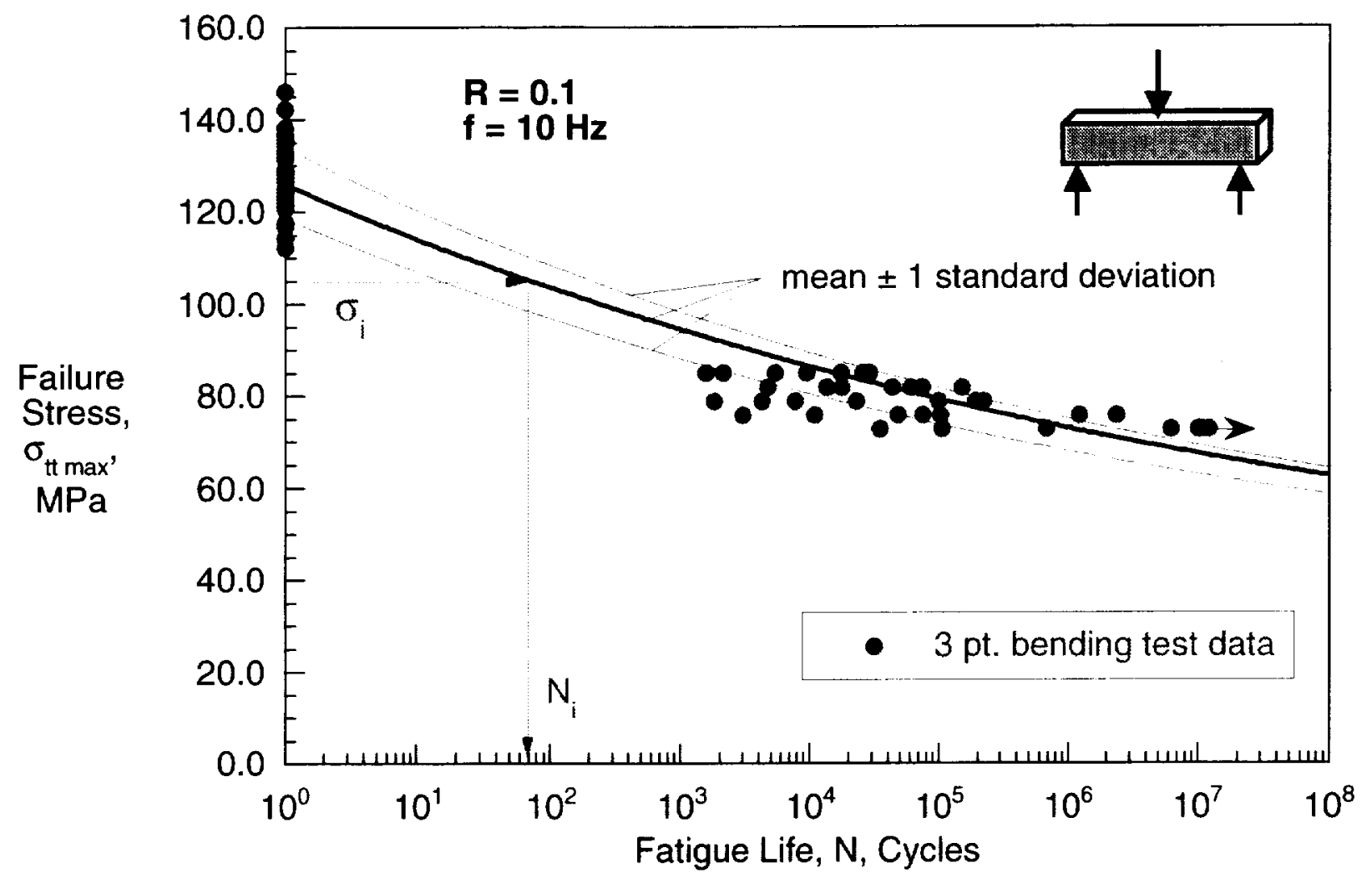

Figure 23. Fatigue life characterization data for matrix cracking onset .

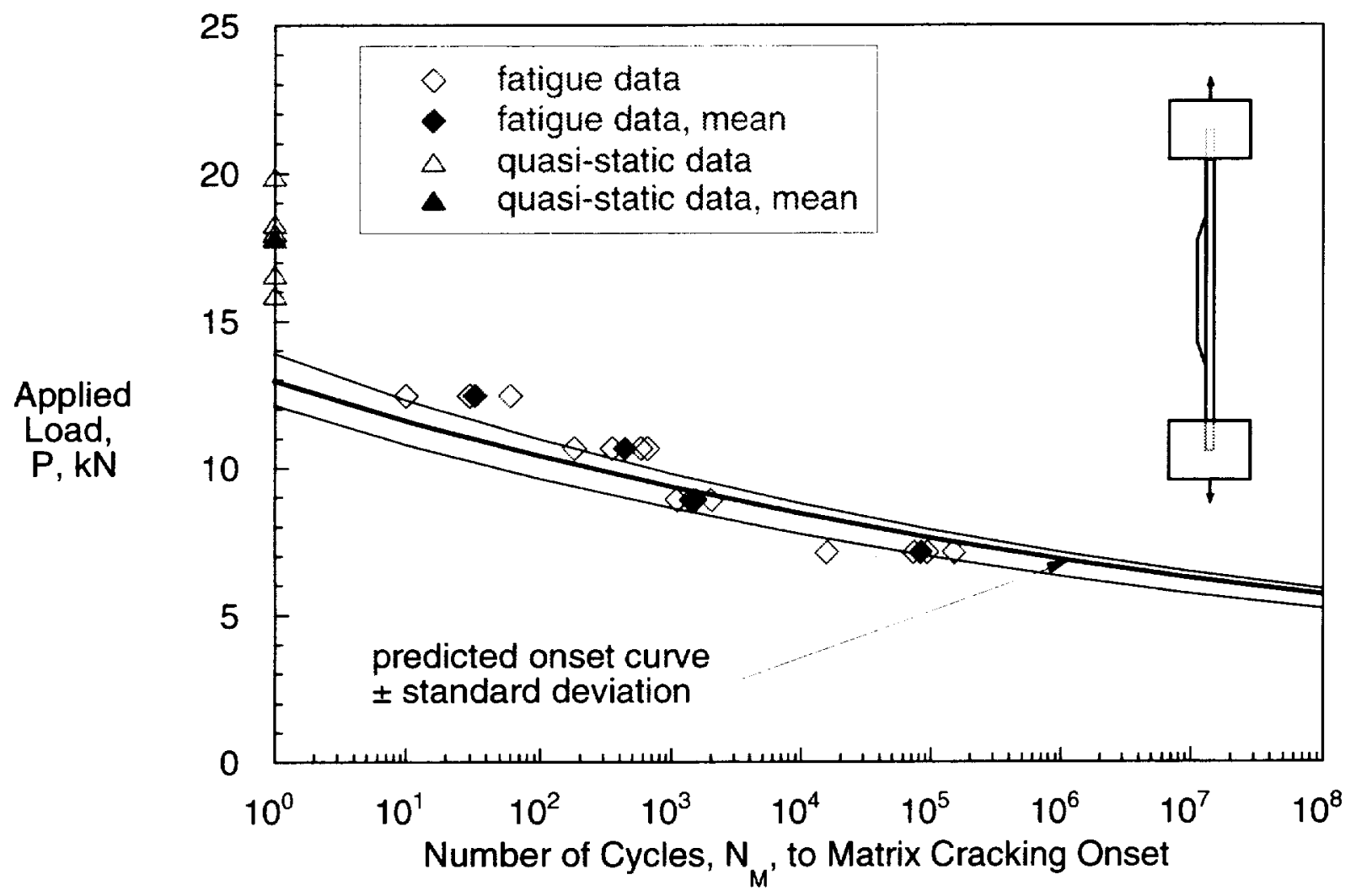

Figure 24. Comparison of matrix cracking onset prediction and experimental results. 


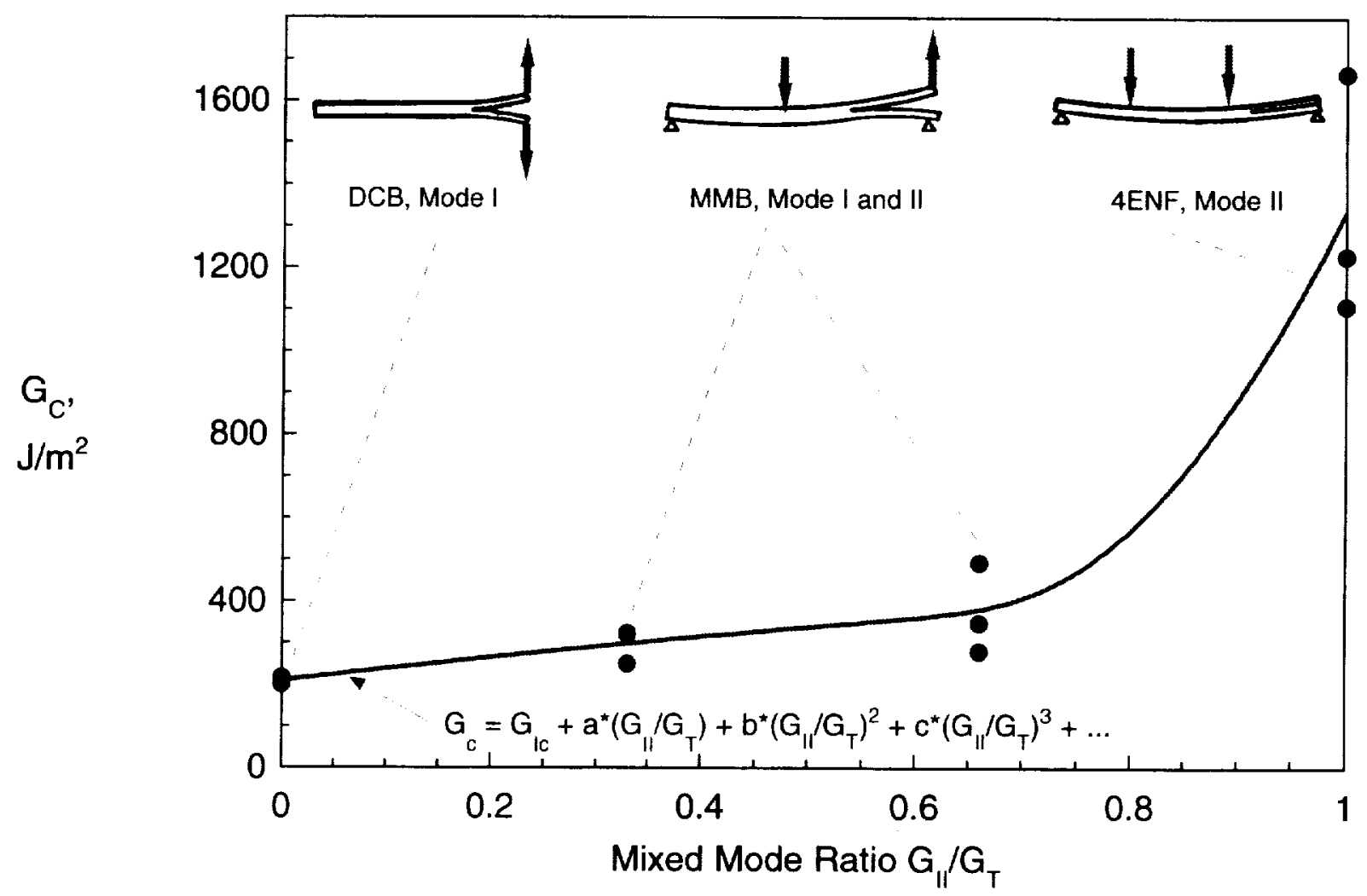

Figure 25. Mixed-mode delamination criterion for IM7/8552

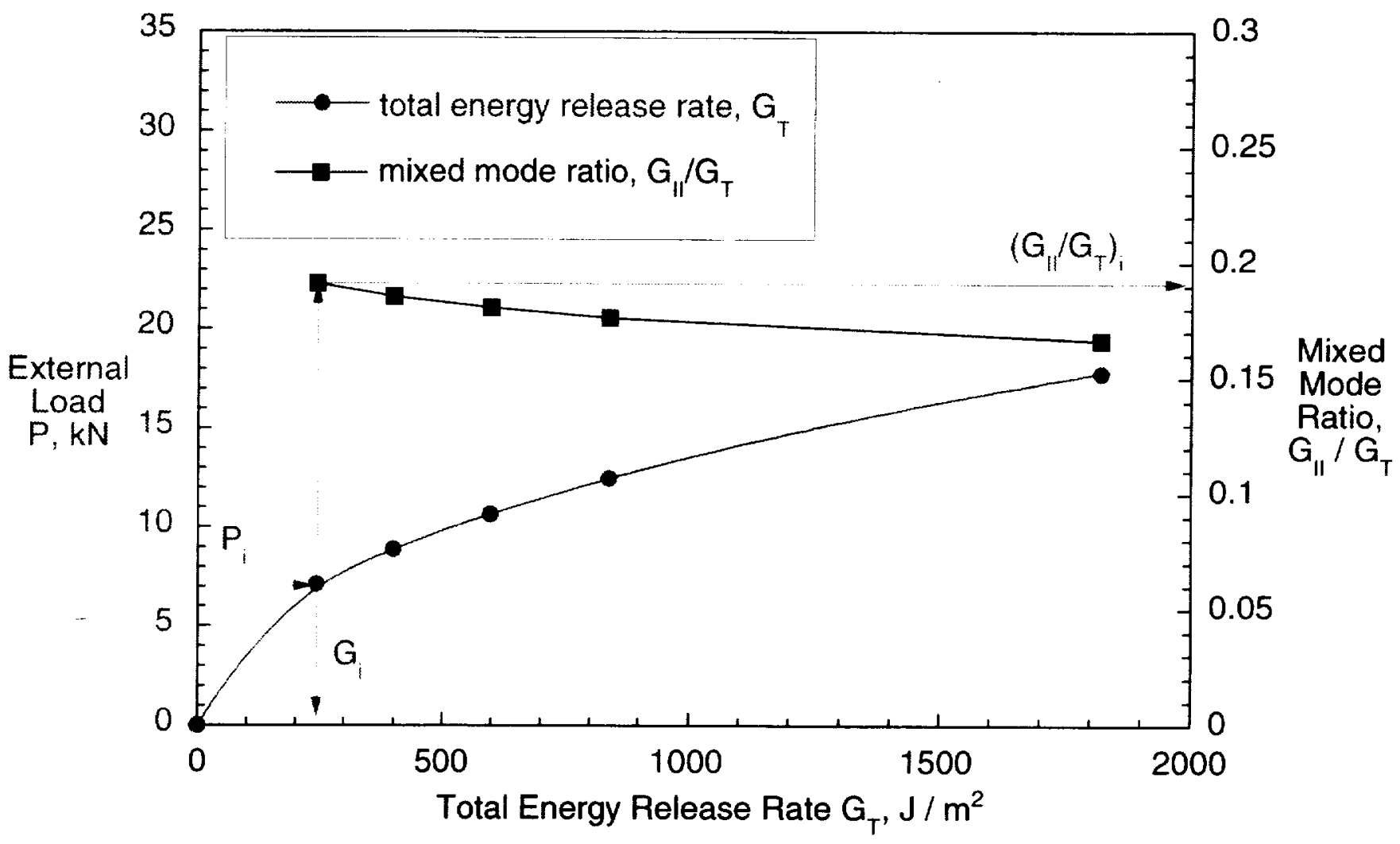

Figure 26. External load and mixed mode ratio plotted versus calculated $G_{T}$ 


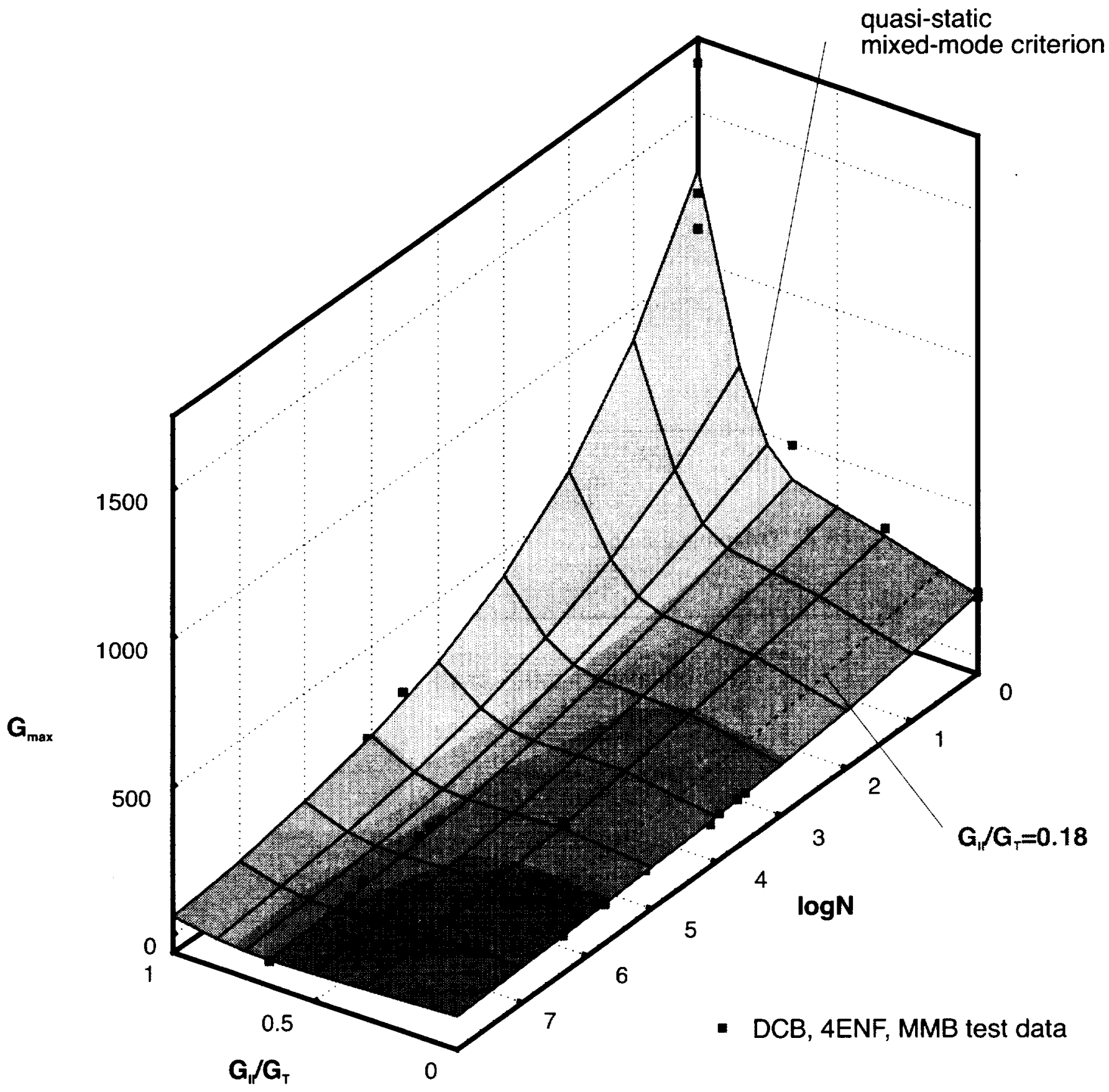

Figure 27. Delamination onset surface for IM7/8552 mixed mode I/II fatigue failure 


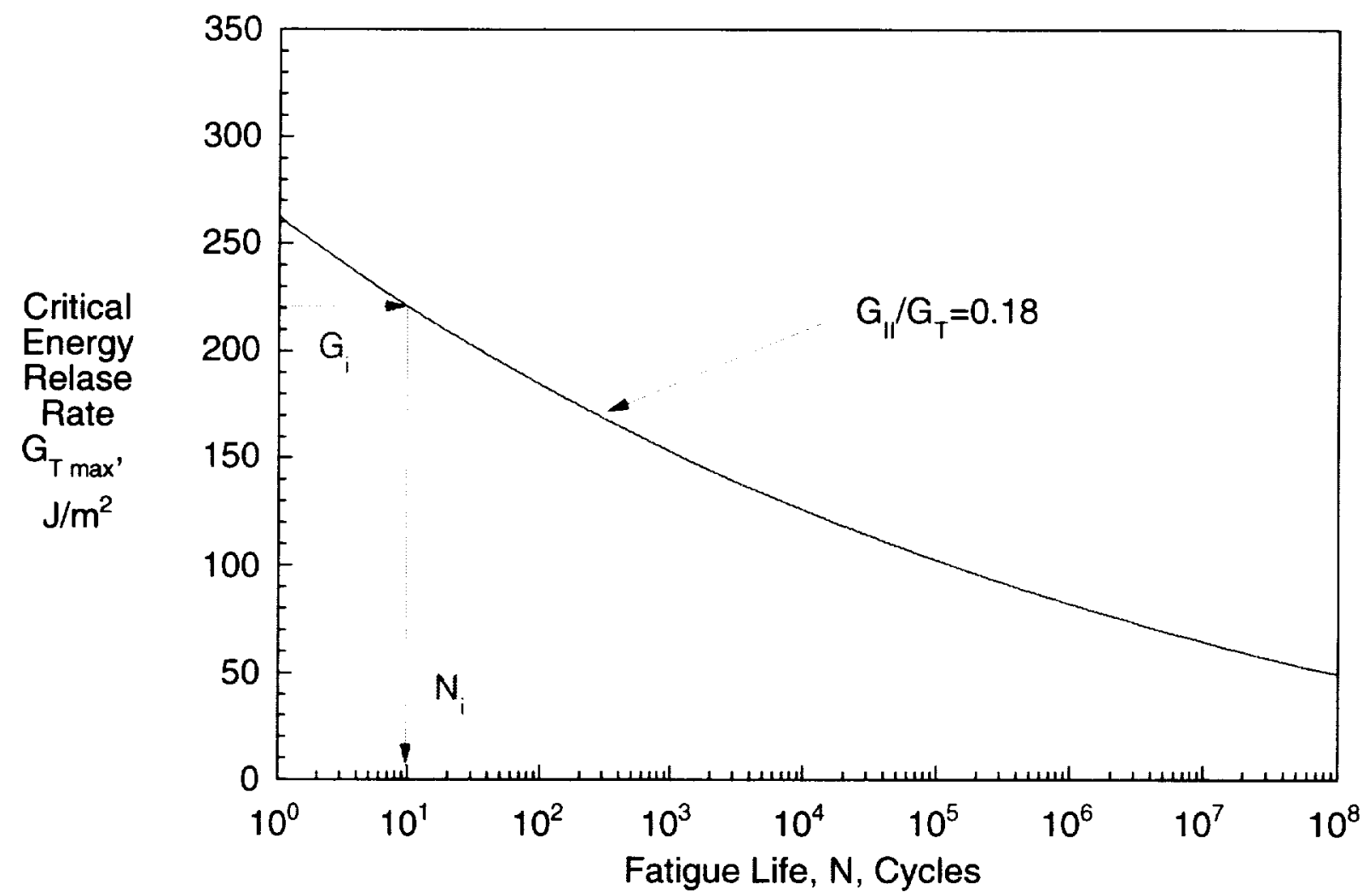

Figure 28. Delamination onset curve for constant mixed mode ratio $\mathrm{G}_{\mathrm{II}} / \mathrm{G}_{\mathrm{T}}$

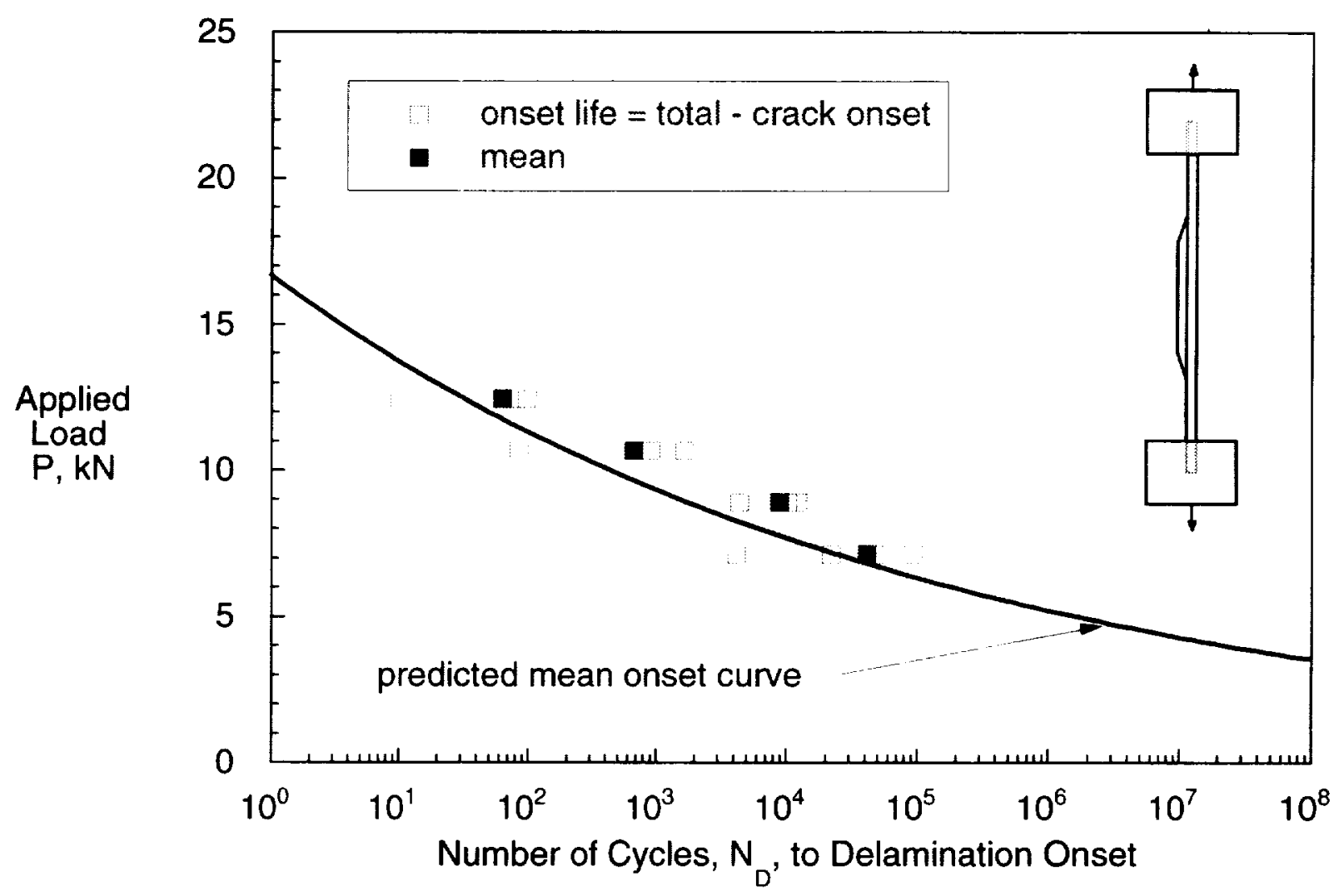

Figure 29. Comparison of delamination onset prediction and experimental results. 


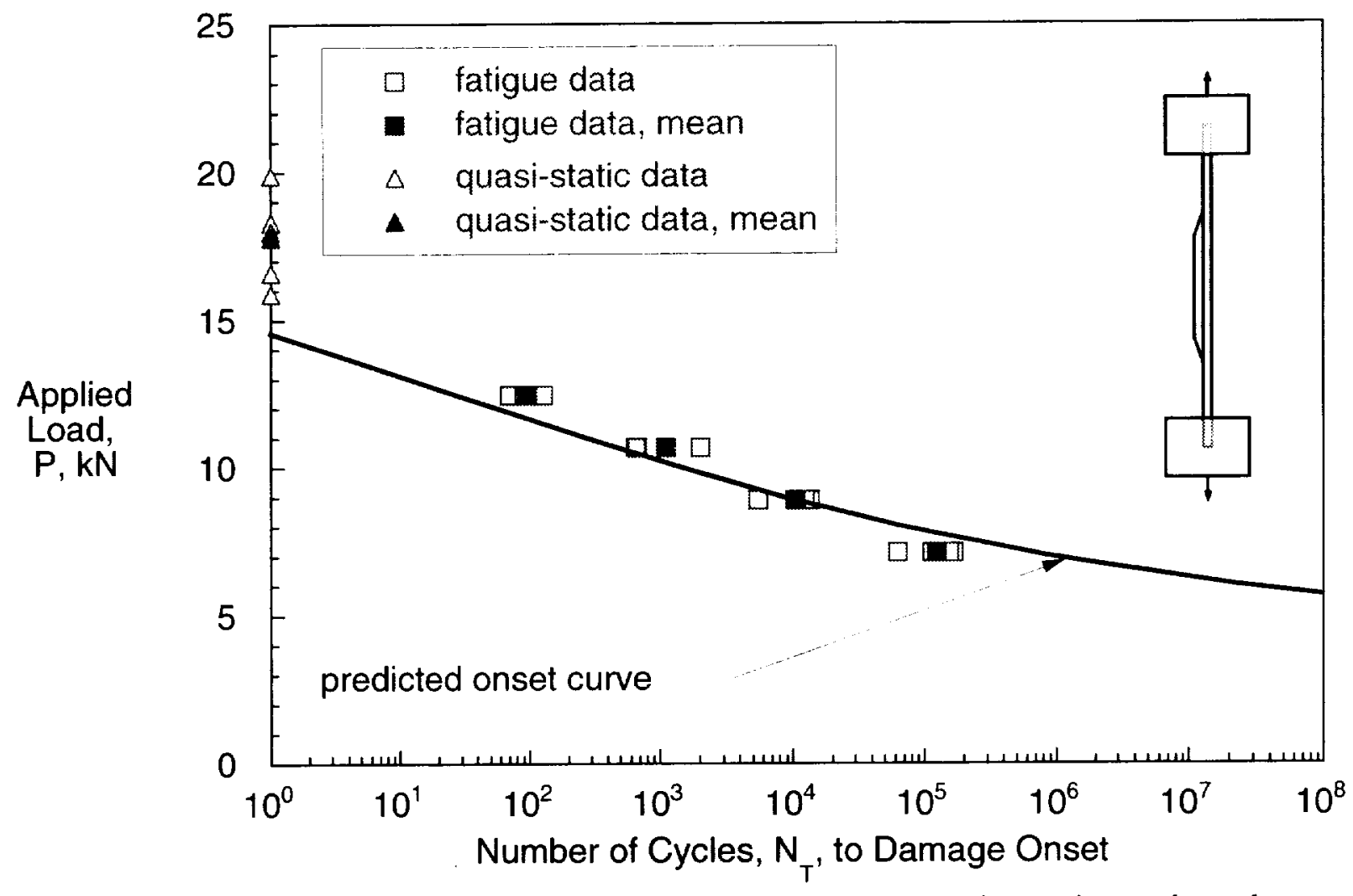

Figure 30. Comparison of cumulative life prediction and experimental results 


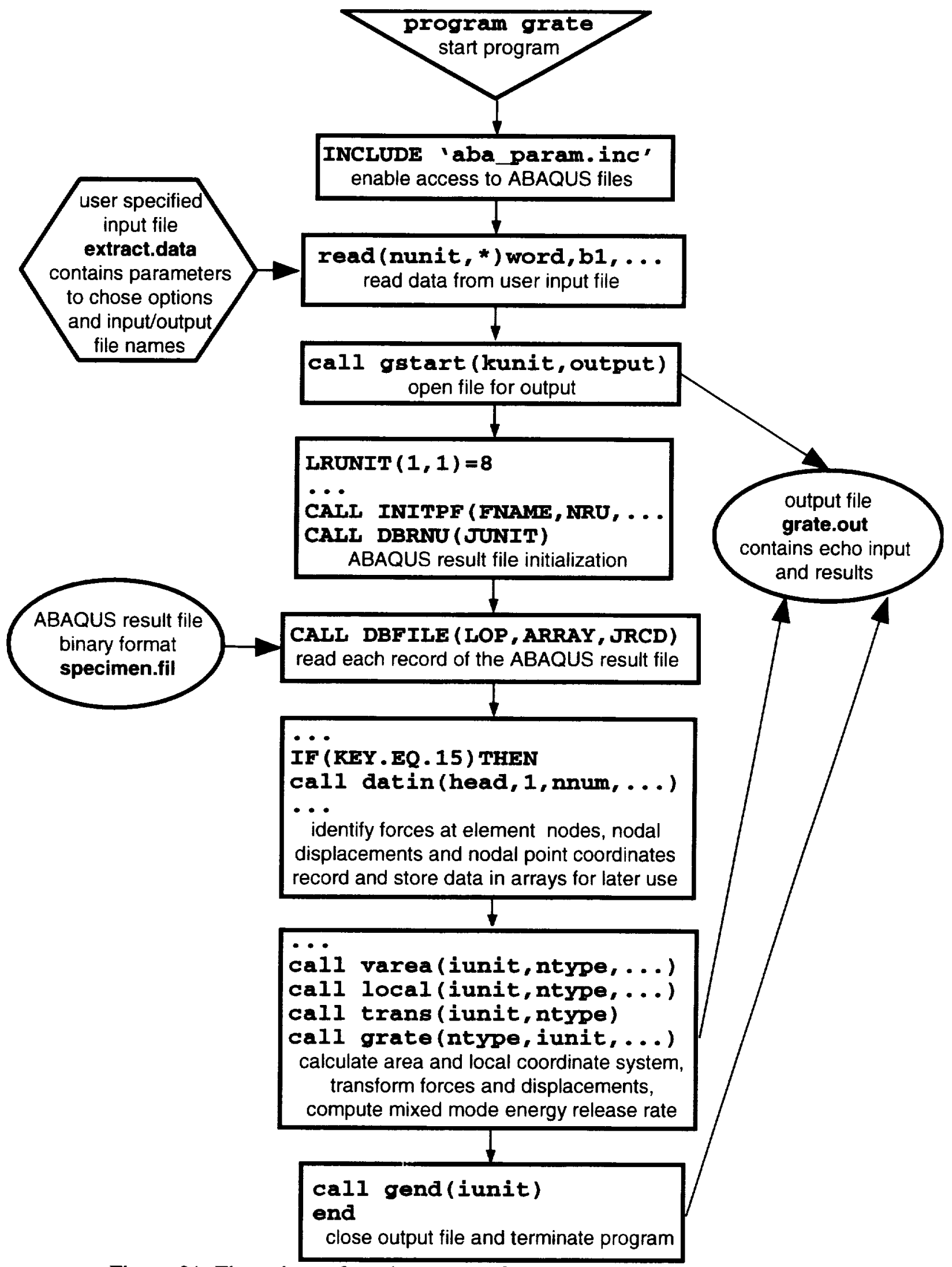

Figure 31. Flow chart of routine extract.f to calculate strain energy release rates. 


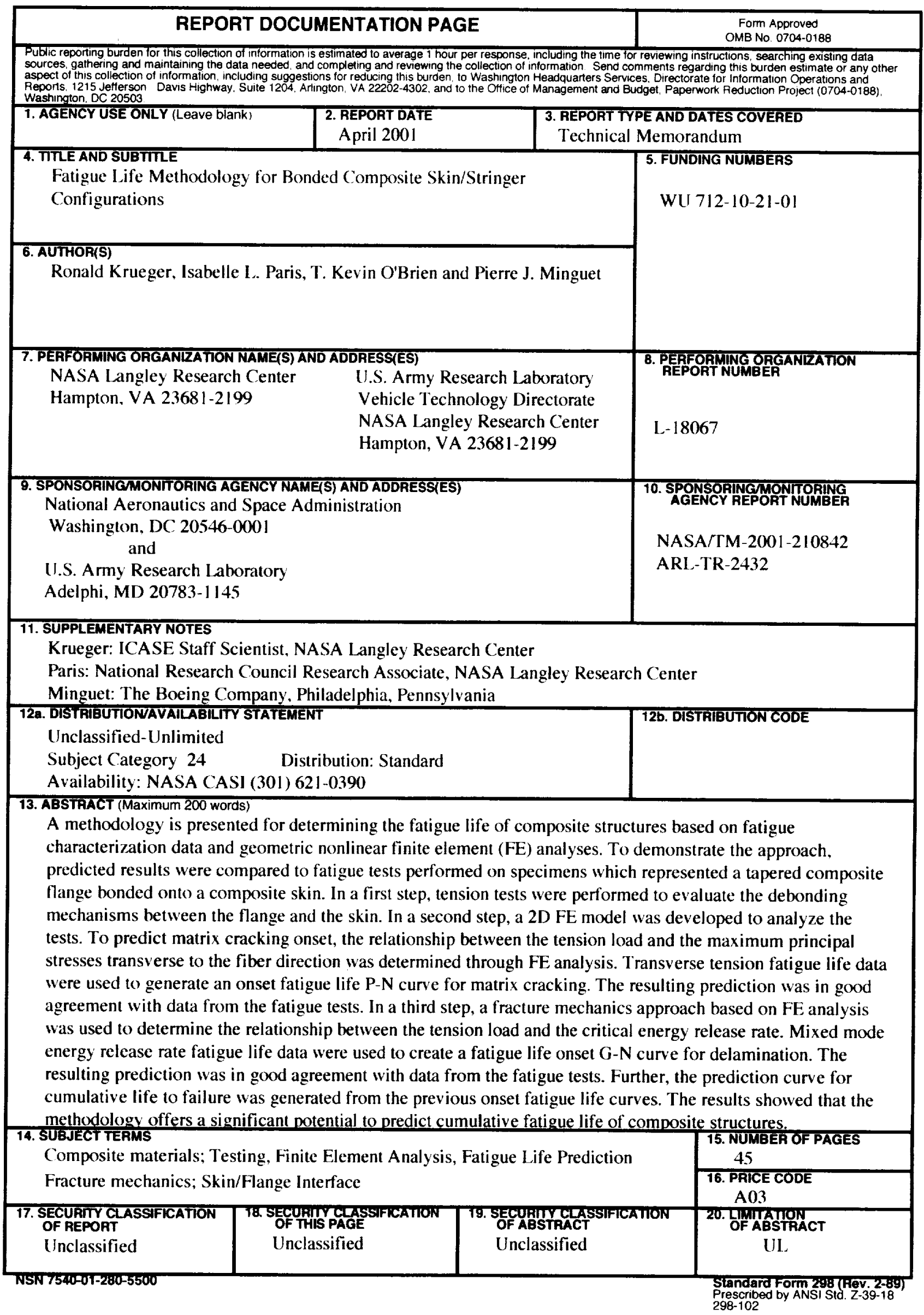


